\title{
Incidents with Dioxins and PCBs in Food and Feed-Investigative Work, Risk Management and Economic Consequences
}

\author{
Rainer Malisch \\ European Union Reference Laboratory (EU-RL) for Dioxins and PCBs in Feed and Food, Chemisches und \\ Veterinäruntersuchungsamt Freiburg (CVUA; State Institute for Chemical and Veterinary Analysis of Food), \\ Freiburg, Germany \\ Email: rainer.malisch@cvuafr.bwl.de
}

How to cite this paper: Malisch, R. (2017) Incidents with Dioxins and PCBs in Food and Feed-Investigative Work, Risk Management and Economic Consequences. Journal of Environmental Protection, 8, 744785 .

https://doi.org/10.4236/jep.2017.86048

Received: April 27, 2017

Accepted: June 25, 2017

Published: June 28, 2017

Copyright $\odot 2017$ by author and Scientific Research Publishing Inc. This work is licensed under the Creative Commons Attribution International License (CC BY 4.0).

http://creativecommons.org/licenses/by/4.0/

\begin{abstract}
The identification of contamination sources within the food chain with polychlorinated dibenzo-p-dioxins (PCDDs) and polychlorinated dibenzofurans (PCDFs), ("dioxins"), and PCBs is difficult and complex. PCDD/PCDF can be formed as unintentional compounds in a number of chemical processes as well as in almost every combustion process. PCBs were intentionally produced chemicals that were manufactured for decades before the ban in marketing and use in many countries around 1985. The pattern of occurrence can change from the original source in particular via feedingstuffs to food of animal origin as result of bioaccumulation. A number of examples illustrate the challenging detective work and key scientific aspects for identification of the sources, for support of the risk management and for performance of monitoring programs. The contamination of milk and milk products in European countries with dioxins was caused by compound feeds containing citrus pulp pellets from Brazil which had high dioxin levels as a result of the use of heavily contaminated lime used for neutralization. The Belgian dioxin crisis was caused by a feed additive heavily contaminated with PCBs which were discharged into a recycled fat used in the production of animal feed. Guar gum from India was contaminated with sodium pentachlorophenate and dioxins. Clay was found to be possibly highly contaminated with dioxins possibly formed by geothermal processes over time; use of such clay as feed additive or for human intake led to elevated dioxin levels in food and humans. Bioanalytical screening in combination with comprehensive physicochemical investigations led to the detection of brominated flame retardants and brominated dioxins in a feed additive. Buffalo milk was contaminated in Italy presumably caused by illegal deposition of waste. High PCB levels in fuel oil for drying of breadcrumb used as a feed ingredient caused a major dioxin crisis with pork
\end{abstract}


meat in Ireland. Fatty acids for technical purposes originating from a biodiesel company were used for production of feed fat which contaminated parts of the food chain in Germany. In addition to effects on human and animal health these incidents also have serious economic consequences which could be mitigated by more frequent control on food and feed. Addressing both these issues, the European Community has developed a strategy to reduce the presence of dioxins and PCBs in the environment and in feed and food comprising the establishment of maximum and action levels.

\section{Keywords}

PCDDs, PCDFs, PCBs, Feed, Food, Detective Work, Congener Patterns, Contamination Incidents, Clay, Geophagy, Biomonitoring, Bromodioxins, EU Legislation, Maximum Levels, Action Levels

\section{Introduction}

PCDDs (polychlorinated dibenzo-p-dioxins) and PCDFs (polychlorinated dibenzofurans), collectively known as "dioxins", can be formed as unintentional by-products in a number of chemical processes and in many combustion processes. Polychlorinated biphenyls (PCBs) are intentionally produced chemicals that were manufactured for decades before adoption of the ban in marketing and use in many countries around 1985; they are also unintentionally formed in processes that generate $\mathrm{PCDD} / \mathrm{PCD}$. Both groups of contaminants are chemically and physically stable, and are thus environmentally and biologically persistent. They are also lipopohilic which results in bioaccumulation in the foodchain in fatty tissues. These chemicals are mixtures of hundreds of closely related compounds or congeners, and the occurrence pattern can change during the transitions from original source to (in particular) feedingstuff and on to food of animal origin. Thus, the identification of sources by identifying contamination patterns is difficult and complex. As these contaminants are not intentionally used food producers are often helpless when asked for possible reasons of findings of elevated levels in their products. However, with regard to the importance of food for human exposure, this detective work is important: It is estimated that about $90 \%$ to $98 \%$ of the average human background contamination with PCDD/ PCDF results from food and that-with consumption habits as in Germany-for adults about $90 \%$ of this intake comes from food of animal origin. Therefore, feedingstuffs are of particular importance for the food chain. The uncovering of several contamination incidents [1] [2] [3] [4] since the 1990s led to a sharp focus on the safety of food chain and resulted in the adoption of safety measures by the European Union (EU). Here, key examples have been selected to illustrate the challenging detective work and key scientific aspects for identification of the sources, for support of the risk management and for performance of appropriate monitoring programs. 


\section{Examples of the Detective Work to Identify the Source of a Contamination in the Food Chain}

\subsection{The "Citrus Pulp" Case}

This first example of the late 1990s shows the complexity of the problem: Three comprehensive studies on two continents were necessary to identify the "real" source. It is a unique example of finding answers to all relevant questions with regard to tracing the source.

\subsubsection{From Contaminated Milk in Germany to Citrus Pulp from Brazil and Changes of Dioxin Patterns from Feed to Food of Animal Origin}

As starting point, the State Institute for Chemical and Veterinary Analysis of Food (CVUA) Freiburg, Germany, found a reversion of the decreasing levels of PCDD/PCDF in cow's milk in 1997: Whereas dioxin levels were gradually declining in Germany as a result of numerous control measures since 1989 to reduce the exposure of humans and the levels in the environment, milk and butter samples collected randomly in early 1998 showed double the usual dioxin content compared with summer 1997. Within the same time-frame increased dioxin concentrations with the same occurrence patterns in products from several parts of Germany and The Netherlands made it clear that this was not a local incident [5]. In all cases the increase in toxicological equivalents (TEQ) was caused by 2,3,7,8-TCDD and 1,2,3,7,8-PeCDD. An immediately performed "emergency collaborative study" confirmed these findings [6].

The key to trace the source was the detection of a high level of $7.86 \mathrm{pg}$ ITEQ/g lipid in milk from a road tanker which had collected milk from 70 farms for transportation to the dairy. An immediate investigation of the 12 biggest farms led to a farm which had $4.83 \mathrm{pg}$ I-TEQ/g lipid-this was about fivefold higher than in previous years. Instantly, a comprehensive inspection covering all kinds of possibilities, e.g. all kinds of feed, paints used for silos, veterinary drugs, pesticides, disinfectants or detergents was conducted on the farm. The results showed that a certain feedingstuff had considerably higher PCDD/PCDF levels than other feeds or vegetable food. This compound feed consisted of six ingredients which at once were analyzed. Two of the ingredients (citrus pulp pellets) had about $6000-7000 \mathrm{pg}$ I-TEQ/kg dry weight which was about 50 times higher levels than those which were seen as usual background levels for feed or vegetable food based on the data of CVUA Freiburg. Also other milk from farms confirmed a correlation between elevated levels in milk and feeding of the compound feed containing citrus pulp pellets (CPP) [7].

A decisive question was then whether the dioxin pattern found in the citrus pulp could explain the pattern found in the milk samples. A comparison of the patterns of citrus pulp (Figure 1; results in $\mathrm{pg} / \mathrm{kg}$ product) and milk (Figure 2; in $\mathrm{pg} / \mathrm{g}$ lipid) does not seem to confirm this hypothesis: Whereas OCDF was by far the predominant congener in CPP, followed by $1,2,3,4,6,7,8-\mathrm{HpCDF}$, the contaminated milk sample calculated on lipid base had a complete different 


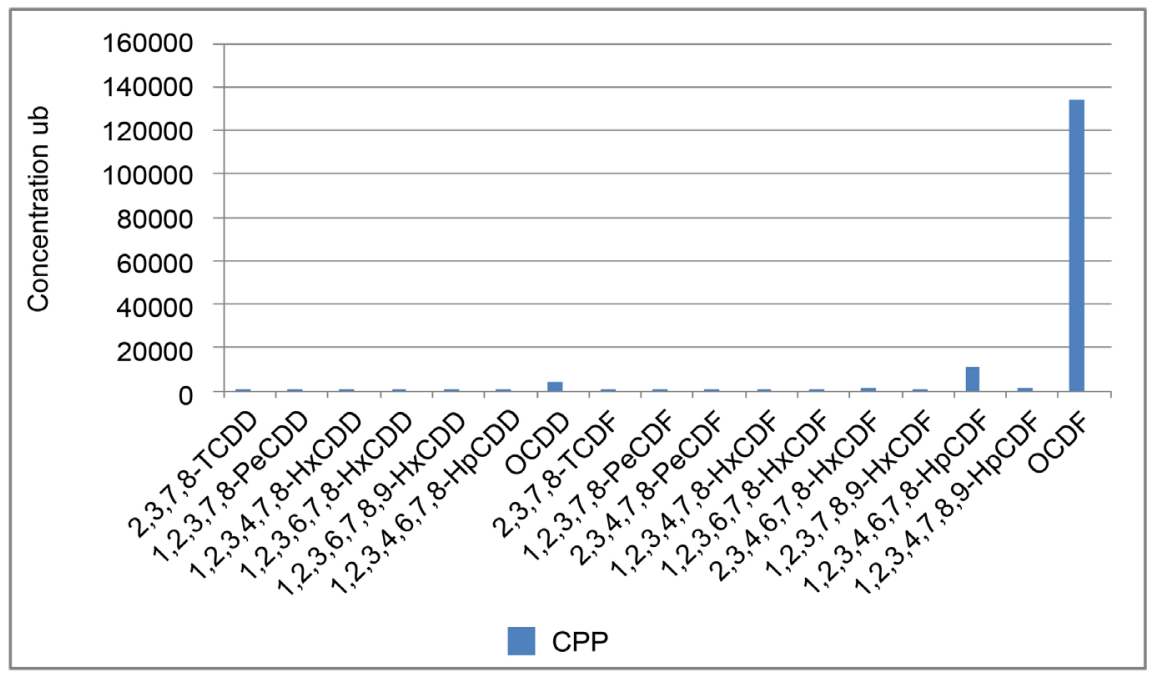

Figure 1. Dioxin pattern of the citrus pulp pellets (CPP), results in $\mathrm{pg} / \mathrm{kg}$ product $(\mathrm{ub}=$ upper-bound levels).

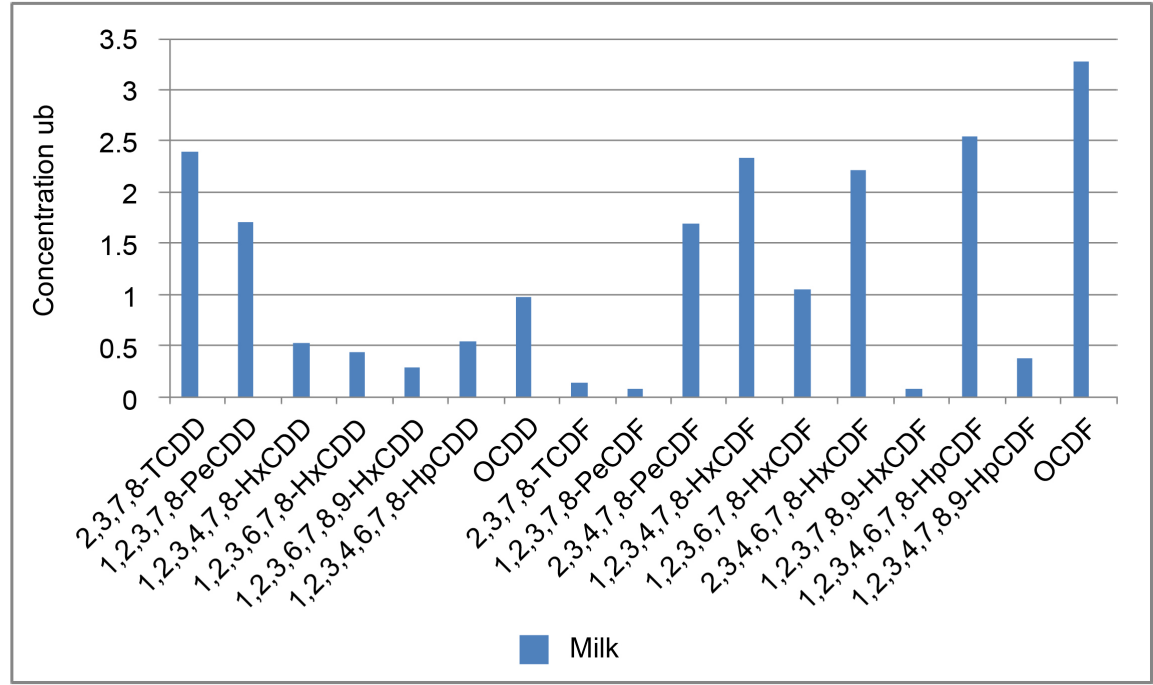

Figure 2. Dioxin pattern of a contaminated milk sample, results in pg/g lipidproduct ( $\mathrm{ub}=$ upper-bound levels).

pattern without this predominance of OCDF and $\mathrm{HpCDF}$.

However, if the levels of the dioxin congeners are calculated as relative contribution (in \%) to the toxic equivalents (TEQs), a totally different picture results: It is then obvious that the toxicologically relevant contamination of both CPP (Figure 3) and the contaminated milk (Figure 4) is caused by 2,3,7,8TCDD and 1,2,3,7,8-PeCDD. This was seen as confirmation of the hypothesis that this CPP had caused the contamination of the milk.

Finally, transfer factors were calculated based on feeding of a maximum of up to $8 \mathrm{~kg}$ compound feed per cow for an increase of the milk production in the high performance phase to about 28 - 30 litres with $4 \%$ fat as follows:

$$
\text { Transfer factor }=c_{m f} / c_{f} * p_{m f} / f
$$

where $c_{m f}$ is concentration in milk fat $(\mathrm{pg} / \mathrm{g}), c_{f}$ is concentration in feed $(\mathrm{pg} / \mathrm{g})$, 


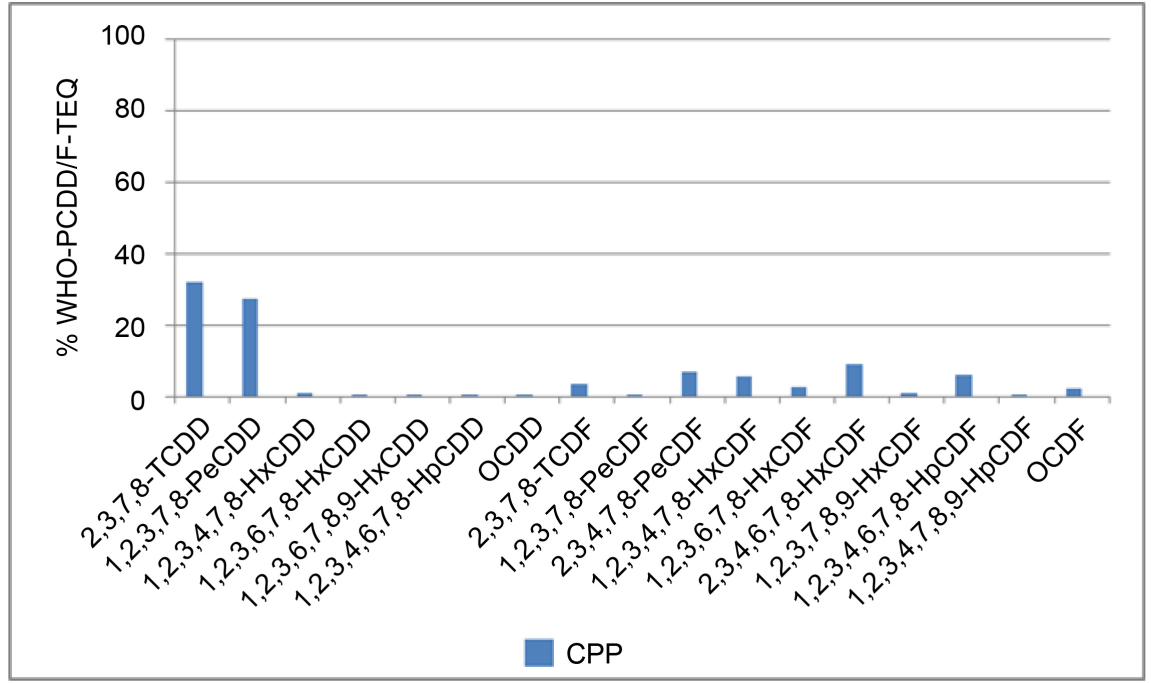

Figure 3. Dioxin pattern of the citrus pulp pellets (CPP), expressed as relative contribution (\%) to WHO-PCDD/F-TEQ.

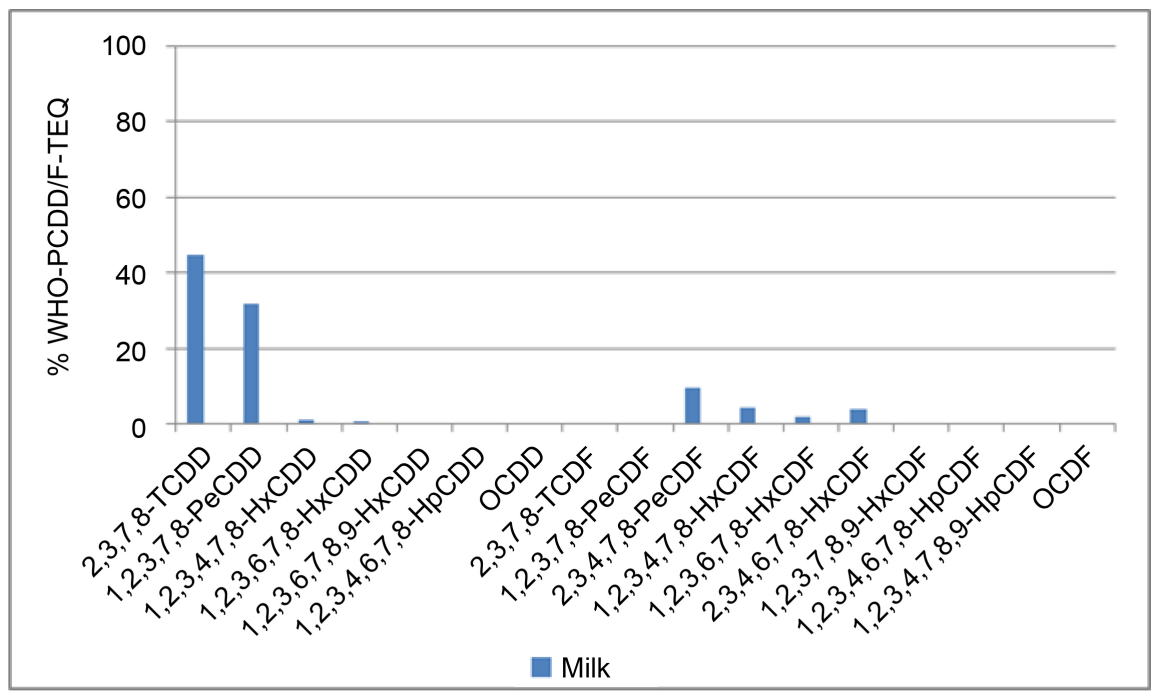

Figure 4. Dioxin pattern of a contaminated milk sample, expressed as relative contribution (\%) to WHO-PCDD/F-TEQ.

$p_{m f}$ is daily production of milk fat $(\mathrm{g})$ and $\mathrm{f}$ is the daily amount of feed intake $(\mathrm{g})$.

The resulting factors for transfer from citrus pulp pellets to milk are listed in Table 1 (from ref. [5]). The factors were compared with findings of Schuler et al for bioaccumulation from grass to milk [8]. Generally, the transfer depends on the congener and on the matrix (e.g. feeding of grass or intake of soil). Even in the Schuler study with feeding of grass over a period of two years with four sampling dates, a range between 0.06 and 0.7 was observed for 2,3,7,8-TCDD, with an average of 0.3 . Therefore, a transfer rate can be calculated only for a specific situation. It was concluded that the transfer factors at least for the predominant congeners were in line with the literature and the observed general tendency (highest transfer rates for 2,3,7,8-TCDD, 1,2,3,7,8-PeCDD and 2,3,4,7,8-PeCDF; low transfer rates for higher chlorinated PCDD/PCDF and 2,3,7,8-TCDF). 
Table 1. Dioxin contamination in milk (pg/g fat), in the compound feed (pg/kg) and the resulting transfer factors (from ref. [5]) with comparison to factors for transfer from grass to milk (Schuler et al., see ref. [8]).

\begin{tabular}{|c|c|c|c|c|c|c|}
\hline & & Milk & Compound & Transfer & Transfer & Factor \\
\hline & & $\mathrm{pg} / \mathrm{g}$ fat & Feed & Factor & Schuler & et al. \\
\hline & & & $\mathrm{pg} / \mathrm{kg}$ & feed-milk fat & mean & range \\
\hline I-TEQ & $\begin{array}{c}\text { (NATO, } \\
1988)\end{array}$ & 4.83 & 1826 & 0.40 & & \\
\hline WHO-TEQ & (1997) & 5.68 & 1965 & 0.44 & & \\
\hline $2,3,7,8-$ & TCDD & 2.39 & 614 & 0.58 & 0.3 & $0.06-0.7$ \\
\hline $1,2,3,7,8-$ & $\mathrm{PeCDD}$ & 1.70 & 524 & 0.49 & 0.2 & $0.08-0.3$ \\
\hline $1,2,3,4,7,8-$ & HxCDD & 0.52 & 153 & $(0.51)$ & 0.08 & $0.05-0.1$ \\
\hline $1,2,3,6,7,8-$ & HxCDD & 0.43 & 85 & $(0.77)$ & & \\
\hline $1,2,3,7,8,9-$ & $\mathrm{HxCDD}$ & 0.29 & 126 & $(0.35)$ & & \\
\hline \multirow[t]{2}{*}{$1,2,3,4,6,7,8-$} & HpCDD & 0.84 & 689 & $(0.18)$ & 0.02 & nd- 0.03 \\
\hline & OCDD & 0.97 & 3960 & $(0.037)$ & 0.008 & $0.004-0.02$ \\
\hline $2,3,7,8-$ & TCDF & 0.13 & 688 & 0.028 & 0.02 & $0.01-0.04$ \\
\hline $1,2,3,7,8-$ & $\mathrm{PeCDF}$ & 0.08 & 325 & 0.038 & 0.04 & $0.02-0.05$ \\
\hline $2,3,4,7,8-$ & PeCDF & 1.69 & 440 & 0.58 & 0.5 & nd- 0.7 \\
\hline $1,2,3,4,7,8-$ & $\mathrm{HxCDF}$ & 2.33 & 1053 & 0.33 & 0.07 & $0.04-0.1$ \\
\hline $1,2,3,6,7,8-$ & $\mathrm{HxCDF}$ & 1.04 & 515 & 0.30 & & \\
\hline $2,3,4,6,7,8-$ & $\mathrm{HxCDF}$ & 2.23 & 1724 & 0.19 & & \\
\hline $1,2,3,7,8,9-$ & $\mathrm{HxCDF}$ & $<0.07$ & $<150$ & - & & \\
\hline $1,2,3,4,6,7,8-$ & $\mathrm{HpCDF}$ & 2.35 & 11,298 & 0.031 & 0.01 & $0.004-0.02$ \\
\hline \multirow[t]{2}{*}{$1,2,3,4,7,8,9-$} & HpCDF & 0.38 & 1366 & 0.042 & & \\
\hline & OCDF & 3.25 & 133,880 & 0.004 & 0.01 & $0.009-0.02$ \\
\hline
\end{tabular}

As a result, bioaccumulation from feed to food of animal origin changes the dioxin patterns considerably. Without consideration of the transfer factors, comparison of patterns between feed and food would cause wrong conclusions. In this case, the transfer factors provided further evidence for the identification of the source.

\subsubsection{Economic and Legal Consequences on a Global Scale}

Immediately after discovery of the dioxin source, other federal states of Germany and the European Union were informed. The contaminated citrus pulp was removed from the market. It turned out that this was an economically important product: Citrus pulp was said to have been produced at about 1.6 million tons/ year worth about 100 - 150 million US-\$. From this huge amount, about 250,000 $\mathrm{t}$ were said to have been imported annually into Germany.

In the EU, about 92,000 t CPP (worth about 10 million US-\$) was discarded or destroyed. 12 member states were affected. The CPP market collapsed. As 
CPP makes up $25 \%$ in compound feed for ruminants, the removal from the market also resulted in shortages of substitute products.

The production of citrus pulp is a seasonal business with two main countries producing CPP at that time: From September to February, CPP was produced in Brazil dominating the world market with a share of about $60 \%$; followed by the US production. Therefore, many countries were involved as producers or consumers (see reference [5]).

The EU regarded the use of highly contaminated citrus pulp as possible risk to human health. Therefore, a temporary maximum level was fixed becoming legally binding in all member states after 1 August 1998 [9].

\subsubsection{Detective Work in Brazil (1): From Citrus Pulp Pellets to Lime}

The reason for the contamination of the CPP was unknown for a long time. The particular PCDD/F pattern did not match the classical contamination patterns. The production process for $\mathrm{CPP}$ restricted the cause of contamination to three possibilities: 1) pesticides in the orange peel, 2) fuel oil containing perchloroethylene as additive, 3 ) ingredients such as lime.

In July 1998, lime was identified as the main source [10]. Lime is added to wet peels, seeds and pulps of oranges in order to facilitate the drying process and to raise the $\mathrm{pH}$ from between 2 and 3 up to between 6 and 7. Lime constitutes about $2 \%$ of the dried CPP. The lime was very high contaminated: up to 2.5 million $\mathrm{pg} I-\mathrm{TEQ} / \mathrm{kg}$. The dioxin pattern of the lime and of the contaminated CPP was very similar.

The total production of lime in Brazil was about 5,750,000 tons a year. The contaminated lime came from one supplier who purchased "lime milk" $\left(\mathrm{Ca}(\mathrm{OH})_{2}\right.$ saturated in water, a by-product of an industrial process) from a chemical company. The lime was primarily used for civil construction. As the lime, which originated from a landfill site of the chemical company, passed the quality control procedures of the supplier (with quality parameters such as heavy metal content or color), it was sold to the CPP market-without knowledge of the dioxin contamination. More information on types of lime and its production was provided to the experts visiting Brazil as missions on behalf of the EU to collect information regarding the investigation of the source and establishment of a control system. However, an explanation as to how the lime was contaminated was not available in 1999 [11] [12] [13].

\subsubsection{Detective Work in Brazil (2): From Lime to Residues of PVC Production Processes}

The origin of the PCDD/PCDFs in the contaminated lime was revealed only in 2008 when the link between the dioxin contamination of the lime milk and the chemical processes of a chlorine/organochlorine industry was found [14] [15]. The landfill site was used for more than 30 years for disposal of lime milk from the vinyl chloride monomer (VCM) production process (for PVC production) and other residues from the company. The factory had used at least two processes with potentially high PCDD/PCDF releases: 1) the oxychlorination pro- 
cess for production of ethylene dichloride (EDC) and 2) the chloro-alkali process. The main landfill waste was lime milk ( 1.4 million tons) from the vinyl chloride monomer production (via the acetylene process) along with residues from other processes. Most samples from the chemical landfill showed an EDCtype PCDD/PCDF fingerprint pattern with a characteristic octachlorodibenzofuran (OCDF) dominance which was found in the citrus pulp pellets.

It was only with these findings, that the very comprehensive detective work was completed, which started with detection of elevated dioxin levels in cow's milk in South-Western Germany, continued with tracing of the source via feedingstuff first to citrus pulp pellets, which were imported from Brazil, then to lime as additive for neutralization and finally to waste from a PVC production process which eventually found its way into the food chain.

\subsection{The Belgian Dioxin Crisis}

\subsubsection{From First Signs of a Contamination to the Identification of the Contaminants}

In February 1999, first signs of a contamination were observed in several poultry farms in Belgium. Symptoms were a sudden drop in egg production, followed a few weeks later by a marked reduction in egg hatchability, a reduced weight gain, and an increased mortality of chicks. Certain lesions resembled the classical manifestations of the "chick-edema disease" which was described in earlier outbreaks of poultry poisoning by polyhalogenated hydrocarbons. These observations led to the suspicion of dioxins as the causative agent. This hypothesis was confirmed in April 1999 after findings of exceptionally high levels of dioxins in chicken fat (958 pg TEQ/g) and feed (781 ng TEQ/kg) [16] and afterwards more than $1000 \mathrm{pg}$ TEQ/g fat in feed, meat, and eggs of affected poultry [17] [18].

In June 1999, additional analyses revealed that these dioxins, as suggested by their patterns, originated from contamination by a commercial PCB oil. Figure 5 shows the patterns of $\mathrm{PCBs}$ and dioxins in contaminated feeds and poultry (from ref. [18]).

\subsubsection{Source of Contamination}

Investigations could trace the source back to nine suppliers of animal feed which all had used the same fat in the production of animal feed. The fat was purchased from one single producer. This company collected oils and fats in waste disposal units at public container parks (in addition to other sources as slaughterhouses or restaurants). The Belgian authorities concluded that the contaminated fat originated from one production tank containing about 80 tonnes produced and sold to feed mill companies between 16 and 31 January 1999 [19]. By extrapolating the $\mathrm{PCB}$ and dioxin concentrations to the volume of the contaminated tank, it was estimated that the total amount of PCBs which was mixed with animal feeds was about $50 \mathrm{~kg}$ PCBs (calculated as sum of seven PCB markers) or about $150 \mathrm{~kg}$ total PCBs, which corresponds to about 100 liters of PCB oil, containing $1 \mathrm{~g}$ TEQ from dioxins and $2 \mathrm{~g}$ TEQs from dioxin-like PCBs. The pattern of PCB congeners was matched to a mixture of Aroclors 1260/1254 (or 


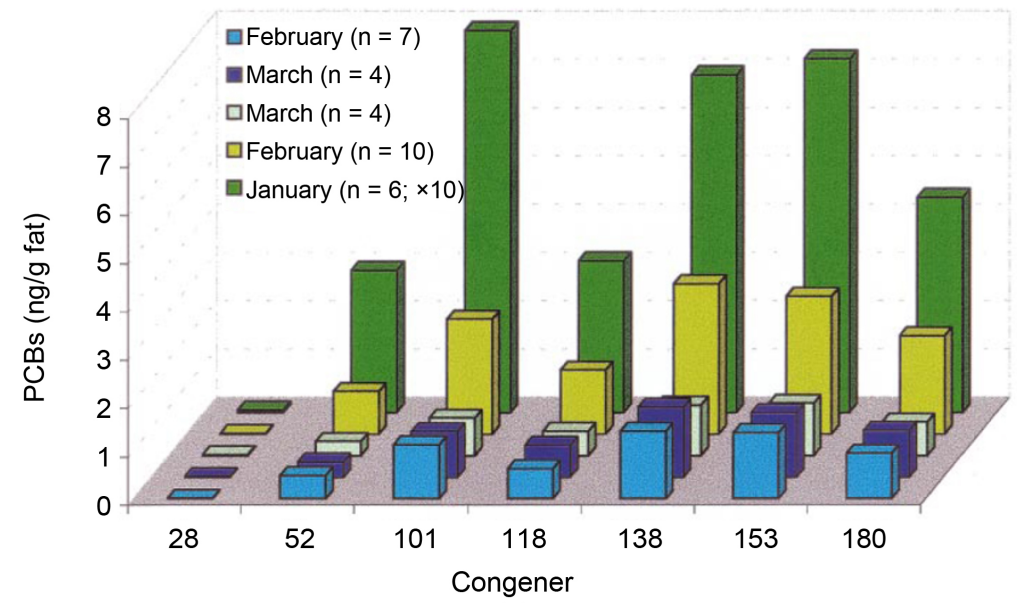

(a)

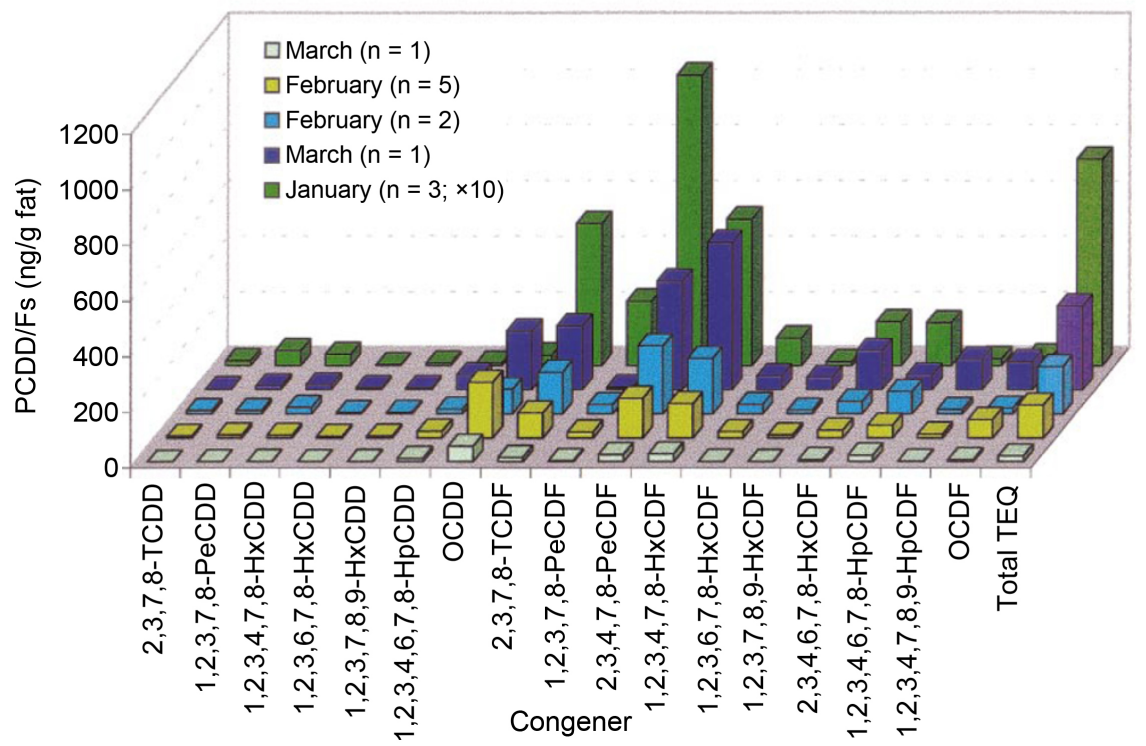

(b)

Figure 5. Patterns of PCB (a) and dioxin (b) congeners in contaminated feeds delivered to pigs (blue bars) and poultry (green bars) farms in January, February and March 1999. Values in poultry feed in January have been divided by 10 (PCBs) or 20 (PCDD/PCDF) for ease of representation (from ref. [18]).

similar commercial PCBs) in the proportions 75/25 [see ref. [17] [18]].

\subsubsection{Monitoring Program and Correlation PCB vs-PCDD/PCDF as Scientific Basis}

The contaminated fat had been used for the production of a wide range of feeding stuffs for poultry, pigs and bovine animals. After tracing all possibly contaminated animal feed, the Belgian authorities placed restrictions on all poultry holdings and pig and bovine farms which had received these products. In May and June 1999, about 2500 farms and 120,000 t feed were subjected to restrictions (Table 2, from ref. [17]).

From June 1999, a large monitoring program was launched to trace the contamination and to identify contaminated products. For intra-Community trade and export to third countries, a system of certification was established. Finally, 
Table 2. Poultry, pig and bovine farms subjected to restrictions in May and June 1999.

\begin{tabular}{ccc}
\hline Type of farm & Under restriction (no of farms) & Mass of products (tons) \\
\hline Poultry & 509 & 40,000 \\
Pig & 1621 & 59,000 \\
Bovine & 409 & 20,700 \\
\hline
\end{tabular}

more than 60,000 samples were analyzed, with about 800 of them for PCDD/ PCDF.

A key element for this monitoring program was the evaluation of the ratio between PCBs (expressed as sum of seven marker congeners) and dioxins (expressed as pg WHO-PCDD/PCDF/g fat, calculated with WHO-TEF 1998). The concentrations of dioxins and PCBs in feeds were very closely correlated, with an average PCBs: dioxins ratio of about 50,000 (Figure 6, from ref. [18]). Also the concentrations of dioxins and PCBs in poultry meat and eggs were concluded to be highly correlated, with PCBs: dioxins ratios almost identical to those in feeds (Figure 7, from ref. [18]). These correlations facilitated the use of PCB measurement results as an indication of dioxin levels-a very important step for an urgent comprehensive monitoring program when one considers the limited capacity for PCDD/PCDF analyses at the end of the 1990s compared to the much higher analytical capacity for PCBs.

In pigs this ratio was non-linear being both much higher and more variable (extremely variable values extending from 50,000 up to 10,000,000), reflecting a faster elimination of dioxins than PCBs in these animals. These metabolic differences also emerged from the PCB and dioxin patterns which were altered much more in pigs than in poultry. Dioxin patterns in dairy cow meat were not different in suspected and unsuspected farms and corresponding to the background contamination.

It must be stressed that the ratio of 50,000 for feed, poultry and eggs is applicable only for this particular contamination episode: It is well known that different PCB products, even different batches of the same PCB product, might be contaminated with different levels of dioxins, in particular depending on the kind of use of the PCB product. Therefore, the EU Scientific Committee on Food accepted the established correlation between PCBs and dioxins for contaminated poultry and egg for this particular incident. Thus, the levels of 7 persistent PCBs could be used reliably as surrogate for dioxins. However, for milk and milk products it was not possible to establish with confidence the same correlation between PCBs and dioxins originating from this contamination incident (see ref. [19]).

\subsubsection{Economic Consequences}

The economic consequences were huge: In September 1999, the direct costs for Belgium were estimated to be about 1 billion ECU (European Currency Unit; replaced on 1 Jan 1999 by Euro with the conversion ratio 1:1), with the indirect costsat about 3 billion ECU. In comparison to this, the costs for analyses were 


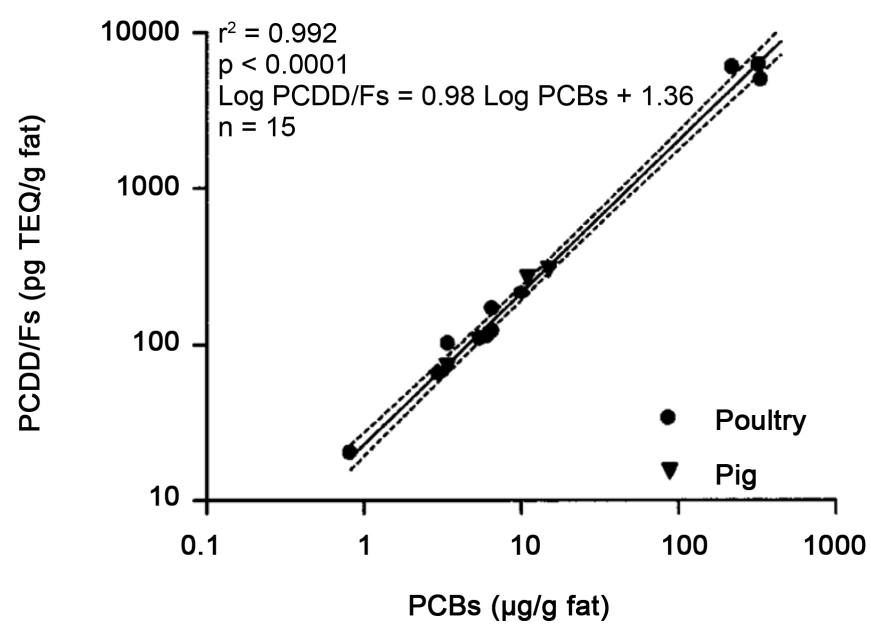

Figure 6. Correlation between PCDD/PCDF as TEQ and PCBs (as sum of seven marker congeners) in contaminated feeds delivered to pig and chicken farm (from ref. [18]).

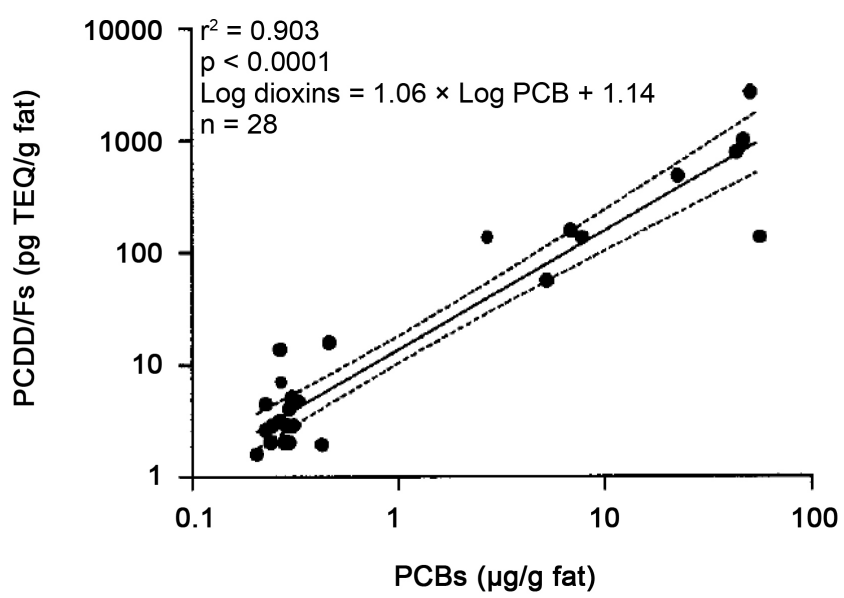

(a)

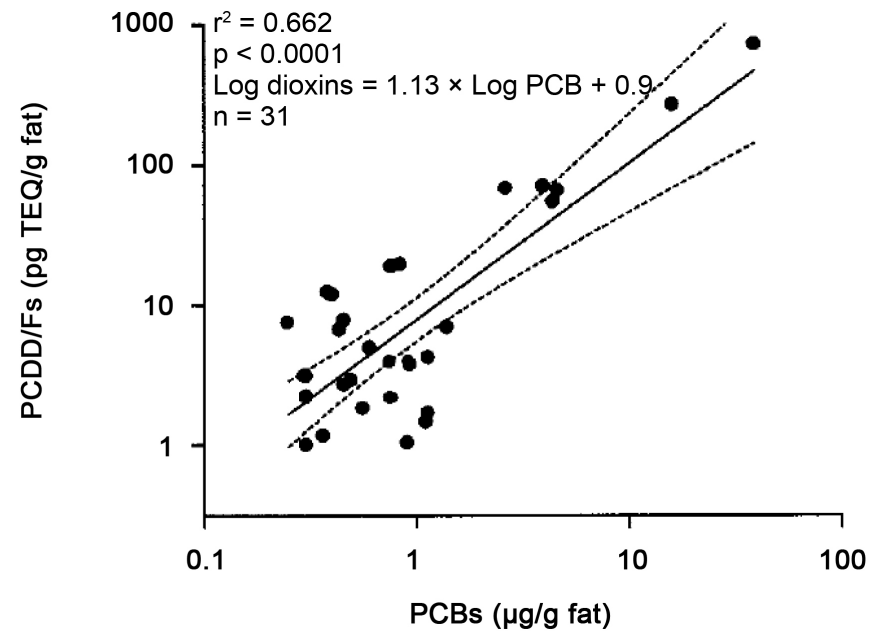

(b)

Figure 7. Correlation between PCDD/PCDF as TEQ and PCBs (as sum of seven marker congeners)in poultry meat (a) and eggs (b) (from ref. [18]). 
negligible [20].

\subsection{Contamination of Guar Gum from India with Pentachlorophenol (PCP) and Dioxins}

\subsubsection{Initial Findings and Dioxin Congener Pattern}

The Rapid Alert System for Food and Feed (RASSF) of the European Commission received on 24 July 2007 a notification from the competent authorities of Switzerland concerning a finding of a serious contamination by dioxins and pentachlorophenol in guar gum originating from India. This contamination incident was reported through the RASSF on 25 July 2007 to all Member States by alert notification 2007.0499 (and additions).

Guar gum is an edible thickening agent extracted from the guar bean. India produced approximately $80 \%$ of the world's total production of guar beans. Two grades of guar gum powder were on the market: 1) a food grade product which is authorized as food additive and used as a thickening, emulsifying, binding and gelling additive in a very wide range of foodstuffs, 2) an industrial grade product for non-food uses.

The contamination levels of dioxins and pentachlorophenol found in certain batches of guar gum were very high. The initially found levels of up to $480 \mathrm{pg}$ WHO-PCDD/F-TEQ/g product and $4 \mathrm{mg} \mathrm{PCP} / \mathrm{kg}$ gave cause for serious concern. Analyses of samples collected to follow up these findings confirmed these high levels in certain batches with even higher levels being detected in a few cases. However, uncontaminated guar gum was also found. With its high dominance of OCDD followed by OCDF and 1,2,3,4,6,7,8-HpCDD, the dioxin pattern confirmed that the presence of dioxins was related to the presence of pentachlorophenol (Figure 8).

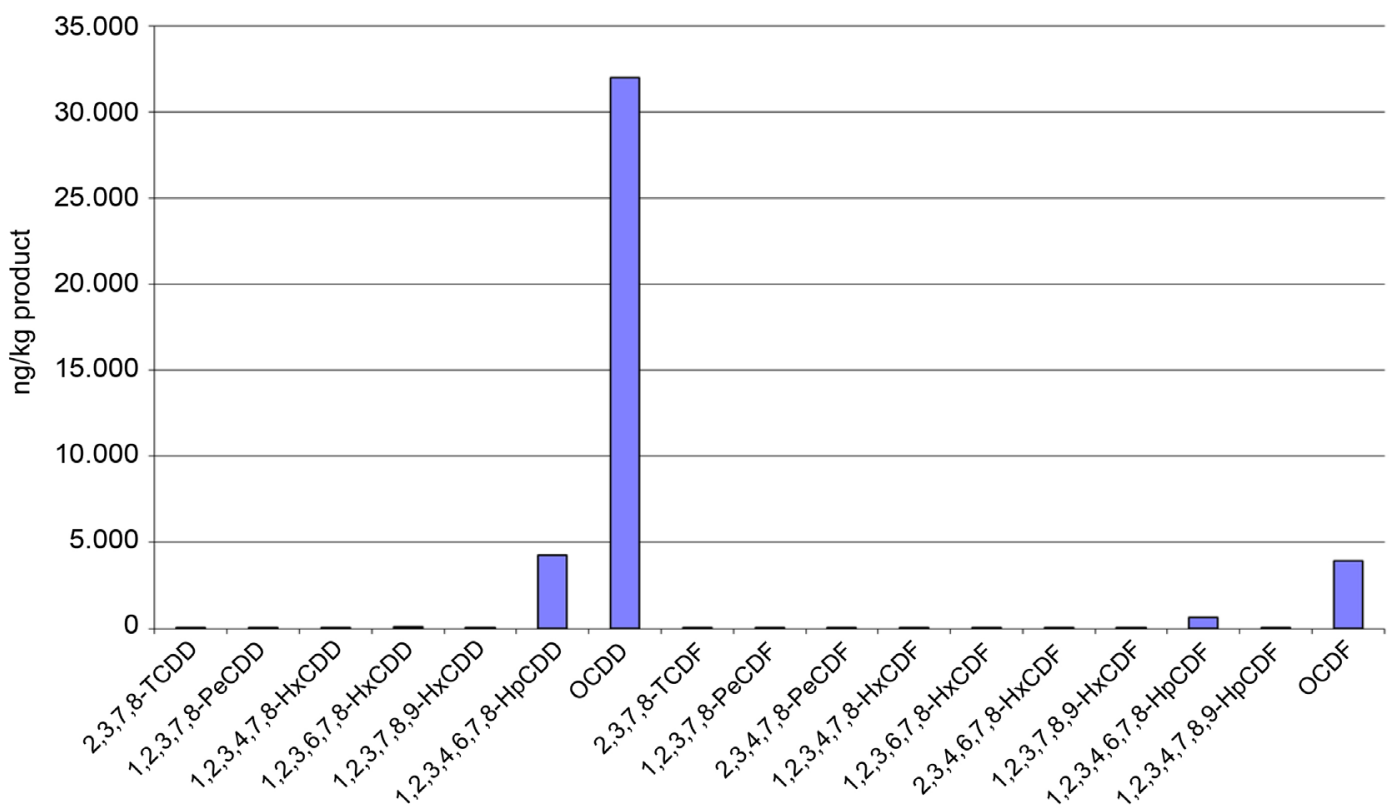

Figure 8. Dioxin pattern of a guar gum sample highly contaminated with PCP (14 mg/kg) and PCDD/PCDF (60.7 ng WHO-PCDD/PCDF-TEQ/kg; using the WHO-TEFs [1998]). 


\subsubsection{Risk Management}

The Commission urged the competent authorities in India to provide more information as regards the source of contamination in order to enable a better assessment of the possible extent of the contamination. The Member States were asked to trace and block contaminated guar gum. In addition, all batches of guar gum originating from the Indian company producing the contaminated product were required to be detained, sampled and analyzed for the presence of pentachlorophenol and dioxins. Reference points of action were set for unacceptable levels of dioxins (0.75 ng PCDD/F-WHO-TEQ $/ \mathrm{kg}$ product) and pentachlorophenol (any quantified level considered as unacceptable, with a default maximum residue level [MRL] of $0.01 \mathrm{mg} / \mathrm{kg}$ [limit of quantification]). In cases where pentachlorophenol was quantified and/or unacceptable levels of dioxins were found, the guar gum could not enter the feed and food chain and had to be safely disposed of. Batches of guar gum from the Indian producer of the contaminated product could only be released after analysis. Furthermore, guar gum from other suppliers in India were required to be sampled and analyzed for a possible presence of pentachlorophenol and dioxins. Where pentachlorophenol was quantified and/or unacceptable levels of dioxins were found, the sampled batch of guar gum had to be traced, blocked and safely disposed of.

\subsubsection{Correlation between PCP and PCDD/PCDF Results including Analytical Aspects}

The EU Commission raised the question to the EU Reference Laboratory (EURL) for Dioxins and PCBs in Feed and Food as to whether PCP analyses would be sufficient as a screening method to ensure that guar gum samples did not exceed the level of $0.75 \mathrm{pg}$ WHO-PCDD/F-TEQ/g product [21]. For evaluation of the correlation between PCP- and dioxin levels in guar gum the available data of analyses of guar gum batches were provided. From a total of 151 batches, 84 were analyzed for dioxins and 57 for PCP. From these, 51 samples were analyzed for both PCP and dioxins. Based on these data, factors were derived for calculation of an individual result from "mg $\mathrm{PCP} / \mathrm{kg}$ guar gum" to "pg WHOPCDD/F-TEQ/g guar gum". Table 3 summarizes the results. An extremely wide

Table 3. Frequency distribution of levels of PCP and dioxins and resulting conversion factors for guar gum samples from India.

\begin{tabular}{cccc}
\hline mg PCP/kg & $\begin{array}{c}\mathrm{pg} \\
\text { WHO-PCDD/F-TEQ/g }\end{array}$ & $\begin{array}{c}\text { Factor for conversion } \\
\text { "mg/kg PCP” to "pg } \\
\text { TEQ/g" }\end{array}$ \\
\hline No of samples & 57 & 84 & 51 \\
Min & 0.02 & 0.05 & 0.86 \\
$25 \%$ Percentile & 0.28 & 2.28 & 8.49 \\
Median & 1.10 & 13.00 & 16.43 \\
$90 \%$ Percentile & 5.42 & 92.04 & 52.00 \\
$95 \%$ Percentile & 15.08 & 156.00 & 76.55 \\
Max & 80.00 & 738.00 & 101.50 \\
\hline
\end{tabular}


range of levels was found for PCP $(0.02$ to $80 \mathrm{mg} / \mathrm{kg})$ and dioxins $(0.05$ to $738 \mathrm{pg}$ WHO-PCDD/F-TEQ/g). The conversion factors for calculation of dioxin levels (in pg WHO-PCDD/F-TEQ/g) from PCP levels (in $\mathrm{mg} / \mathrm{kg}$ ) ranged between about 1 and 100, with an average (mean) of about 25 and a median of 16.4.

Different reasons were considered for these extremely wide ranges:

- Contamination by different batches of PCP: As an example, results of 2.04 and $2.67 \mu \mathrm{g}$ BGA-TEQ/g (TEF factors proposed by the German Bundesgesundheitsamt [BGA; Federal Health Institute] in 1985) for two PCP products (Witophen $\mathrm{P}$ and Rhone Poulenc) respectively 0.51 and $0.09 \mathrm{pg}$ BGA-TEQ/g for two Na-Pentachlorphenol products (Dowicide and Preventol) were reported [22].

- During processing of guar gum, dioxin levels could possibly change, e.g. by formation from precursors at heating processes.

- Analytical results seemed to be unreliable in some cases. As an example, a certain batch was analyzed by the EURL for Dioxins and PCBs (Freiburg, Germany) and the EURL for Pesticides with Single Residue Methods (Stuttgart, Germany) with a result of $457 \mathrm{pg}$ WHO-PCDD/F-TEQ/g and 33.4 $\mathrm{mg} / \mathrm{kg}$ PCP, whereas another labhad found $406 \mathrm{pg}$ WHO-PCDD/F-TEQ/g and $4 \mathrm{mg} / \mathrm{kg}$ in the same batch (Table 4). This reported low level of $4 \mathrm{mg} / \mathrm{kg}$ PCP seemed to be a considerable underestimation of the "true value" (factor of 8 too low).

In contrast to the wide range of correlation factors derived from the reported results, the results of the two EURLs (with determination of PCP at EURL Stuttgart and of dioxins at EURL Freiburg; former names "Community Reference Laboratory", CRL) showed a very high correlation (see Figure 9 "Correlation TEQ-PCP CRL Freiburg"; R² = 0.9999) [23].

The considerable underestimations of the PCP levels were found to be the result of insufficient extraction due to the use of the wrong $\mathrm{pH}$ adjusted extracting solvent: According to reports of CVUA Münster, Germany, a sample highly contaminated with dioxins (485 pg WHO-PCDD/F-TEQ/g) had a relatively low level of about $5 \mathrm{mg} / \mathrm{kg}$ PCP when directly extracted with an organic solvent (acetonitrile). However, extraction with acidified acetonitrile (mixed in a proportion of 9:1 with $2.5 \mathrm{n} \mathrm{HCl}$ ) resulted in a 10 -fold increase to about $59 \mathrm{mg} / \mathrm{kg}$ PCP. Initially, EURL Stuttgart used the QuEChERS-method (extraction with acetonitrile, acidified with $0.4 \%$ acetic acid) and later modified to acidification with citrate salts; $\mathrm{pH}$ 5.(For the latest version for analysis of PCP in guar gum see [24]). These findings were a strong indication that Na-pentachlorphenol rather

Table 4. Comparison of results of a guar gum sample obtained by the EU Reference Laboratories in comparison to results obtained from self-control.

\begin{tabular}{ccc}
\hline Results & PCP $(\mathrm{mg} / \mathrm{kg})$ & WHO-PCDD/F-TEQ $(\mathrm{pg} / \mathrm{g})$ \\
\hline $\begin{array}{c}\text { EURLs Stuttgart/Freiburg } \\
\text { Laboratories conducting } \\
\text { self-control }\end{array}$ & 33.4 & 457 \\
\hline
\end{tabular}




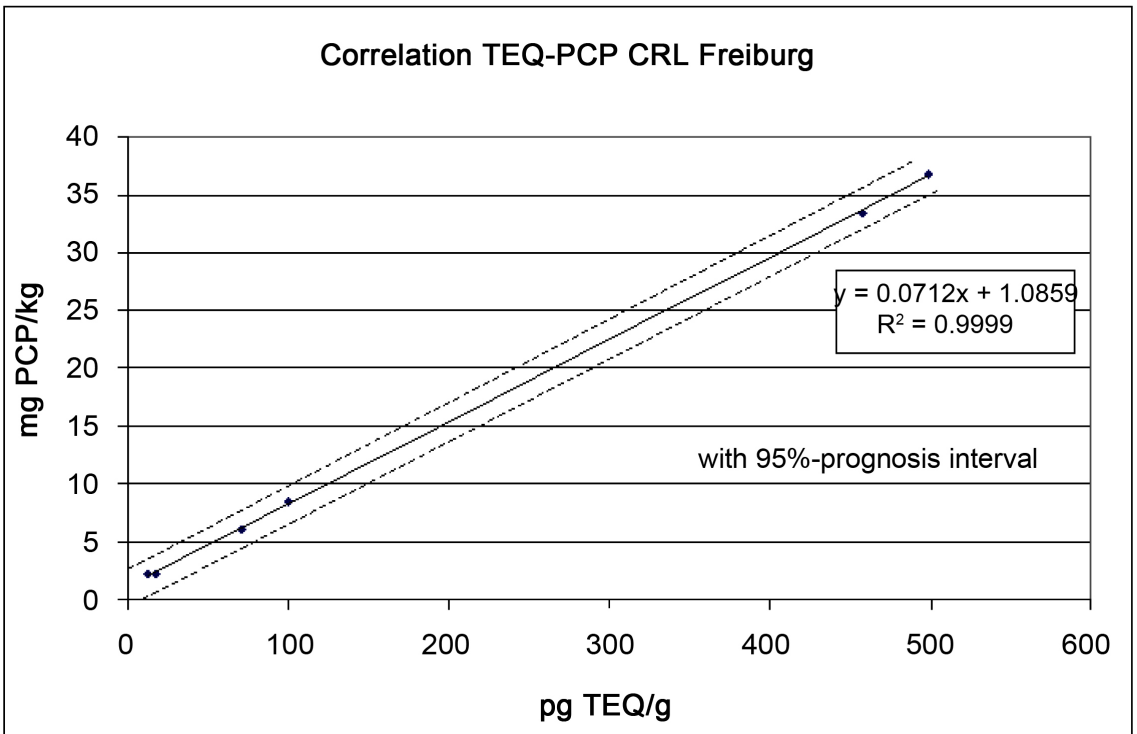

Figure 9. Correlation TEQ-PCP according to results of the EURLs (former names "Community Reference Laboratory", CRL) with determination of dioxins at CRL for dioxins and PCBs, Freiburg, Germany, and of PCP at CRL for pesticides/single residue methods, Stuttgart, Germany.

than pentachlorophenol was used in India. As a result from the analytical perspective, the control of the correct $\mathrm{pH}$ value is important to make sure that both pentachlorphenol and Na-pentachlorphenol can be extracted from a sample.

\subsubsection{Global Proficiency Test for Determination of PCP and PCDD/PCDF}

With regard to the global trade of this guar gum originating from India and the analytical difficulties to determine PCP correctly, the two EURLs for dioxins and pesticides (single residue methods) performed a world-wide proficiency test with determination of PCP and PCDD/PCDF in two guar gum samples (one in the range of the legal limits, one about 50-times higher). 53 official and private laboratories participated using GC/MS methods for determination of PCDD/F and PCB, 9 laboratories using bioassays. 41 laboratories analyzed for PCP.

The PCDD/PCDF concentration of one sample (sample A) was in the range of the maximum level of $0.75 \mathrm{ng} \mathrm{WHO}-\mathrm{PCDD} / \mathrm{F}-\mathrm{TEQ} / \mathrm{kg}$ product (1.18 $\mathrm{ng} \mathrm{WHO}-$ $\mathrm{PCDD} / \mathrm{F}-\mathrm{TEQ} / \mathrm{kg}$ product). The other one (sample B) had about 50 -times higher dioxin levels (60.7 ng WHO-PCDD/F-TEQ/kg product). Both samples reflected the concentration range in the guar gum incident of 2007. The distribution of the results of all participants was similar for both concentration levels. $71 \%$ of the participating NRLs were within the acceptable range of $\pm 20 \%$ of the consensus value for WHO-PCDD/F-TEQ. A clear overestimation of more than a factor of two with CALUX bioassay was found for both concentration levels. This overestimation was seen as result of the differences between the REP- and TEFvalues for the most abundant congener 1,2,3,4,6,7,8-HpCDD [25] [26].

The PCP results showed a very broad distribution with robust RSD values clearly exceeding the levels typically achieved for pesticide residues in food. The distribution of results from laboratories which applied the modified QuEChERS 
method for analysis of PCP in guar gum samples were significantly lower compared to the distribution of results from laboratories using other methods [27].

\subsubsection{EU Missions to India}

The EU Food and Veterinary Office carried out a mission in India from 5 to 11 October 2007 to gather information on the possible source of contamination and to assess the control measures put in place by the Indian authorities to avoid the re-occurrence of this contamination [28]. The mission team noted that sodium pentachlorophenate was produced and readily available in India. It had been used extensively in the production of industrial grade guar gum and was still marketed for this purpose at the time of the mission, although its use was denied by the competent authority and visited producers. It was concluded that the contamination was likely to be either due to the chemical being added intentionally or accidentally to industrial grade gum, and the subsequent use of industrial grade gum for food use, or cross-contamination from industrial to food grade gums due to lack of separation of the two processes.

The Indian authorities conducted an investigation that concluded that there was no generalized contamination, but that some low levels of both PCP and dioxins were found. The investigation by the Indian Authorities did not focus on identifying a source of contamination linked to contaminated products exported to Europe. Thus the competent authority had not identified a source of contamination in the affected lots.

A follow-up inspection mission of the FVO took place in India from 1 to 12 October 2009 to assess the control measures put in place by the Indian authorities to prevent contamination of guar gum with pentachlorophenol (PCP) and dioxins and to follow-up the recommendations of the mission that took place in October 2007. The mission team noted that sodium pentachlorophenate was produced and still available in India, and still advertised as being for use in the guar gum industry. Several serious deficiencies were observed during the mission and the findings indicate that the contamination of guar gum with PCP cannot be regarded as an isolated incident and that only the effective analysis by the approved private laboratory has prevented the contaminated product from being further exported to the European Union. There was no improvement in the control system and no significant reduction in the risks associated [29].

\subsubsection{Safeguard Measures in EU}

As immediate safeguard measures to protect public health, Commission Decision 2008/352/EC imposed special conditions governing guar gum originating in or consigned from India due to contamination risks of those products by pentachlorophenol and dioxins [30]. The measures required that all consignments of guar gum or products containing guar gum at significant amounts originating in or consigned from India and imported into the Community intended for human or animal consumption, should be accompanied by an analytical report, endorsed by the competent authority from the country where the laboratory which has performed the analysis is located. Based on the results of the second 
mission to India, the measures were reviewed and Commission Regulation (EU) No 258/2010 was adopted. In 2015, the source of contamination was seen as not yet eliminated and therefore it was considered appropriate to maintain special conditions for import. Regulation (EU) No 258/2010 was repealed and replaced by the new Commission Implementing Regulation 2015/175 [31].

\subsection{Contamination of Clays with Dioxins}

\subsubsection{First Findings of Elevated Dioxin Levels in US Food Contaminated by Ball Clay from Mississippi}

In 1994, farm-raised catfish contained by far the highest levels of PCDD/PCDF in a study of food samples from supermarkets in Mississippi [32]. As a followup, catfish feed samples and eight feed ingredients were analyzed. One of the ingredients, soybean meal, was highly contaminated by PCDDs. The congener pattern was quite unique. No environmental sample or technical product with similar characteristics was known at the time. As a result, natural formation of the PCDDs found in the soybean meal could not be ruled out [33].

In 1997, the US-EPA published results of a survey on dioxin-like compounds in US poultry animals. Two poultry samples had concentrations of 2,3,7, 8TCDD toxic equivalents (TEQ) which were by more than one order of magnitude higher than found in all other groups [34]. The contamination was traced to a flowing agent, ball clay (fine-grained hydrated aluminium silicate with higher organic content than other clays), in the soybean component of the animal feed. The ball clay originated from a single mine in Mississippi and was a minor component $(<1 \%)$ of not only the chicken feed but also of cow feed pellets and catfish nuggets. The latter use could explain also the first mentioned findings in fish. The US Department of Agriculture estimated that $51 \%$ of the animal feeds contained the TCDD containing ball clay. One percent of the egg production in the United States would equal approximately 1.7 million eggs per day. An earlier nationwide sampling of retail catfish by the U.S. Food and Drug Administration (FDA) revealed that at least $35 \%$ of all the U.S. farm-raised catfish contained elevated TCDD, probably arising from ball clay. The FDA stopped further distribution of contaminated soybean meal by the two manufacturers in Arkansas. Based on these reports and findings of elevated dioxin levels in chicken eggs and farm-raised catfish, the US Food and Drug Administration (FDA) terminated the use of ball clay from this mine in Mississippi as an additive in animal feed [35]. However, for a long time the reason for this contamination remained unclear.

\subsubsection{Dioxins in Kaolinic Clay from a Region in Germany, in Sediments from Australia and Hypothesis of Natural Formation}

As response to the Belgian dioxin crisis, an intense monitoring program covering various kinds of food and feed matrices was performed in many European countries in May and June 1999. As a result of this, in June 1999, the Austrian authorities informed the EU Commission and Germany of findings of a high dioxin contamination in kaolinic clay samples (174 ng I-TEQ/kg) which were 
traced back to Germany. The contaminated clay was produced by a mine in the Westerwald area. The pattern was unknown (rising concentrations from TCDD to OCDD, no PCDF detectable).

As result of a comprehensive study at the instigation of the competent German authorities, PCDDs at considerable levels (TEQ-values up to several hundred $\mathrm{ng} / \mathrm{kg}$ ) were found in dominantly kaolinite-type natural clay minerals. Contrary to expectations, PCDFs were not detected at all. As a conclusion an anthropogenic influence was seen as highly unlikely, whereas most likely a "natural" formation was assumed [36].

Research in Australia's north east detected high concentrations of PCDDs and in particular OCDD in coastal sediments. The results provided evidence that an unidentified source for higher chlorinated PCDDs exists along the Queensland coast [37] [38]. In addition, high OCDD concentrations were also found in blubber samples collected from dugongs (Dugong dugon) which were found stranded within Australia's Great Barrier Reef Marine Park [39].

As conclusion of these findings of the same dioxin patterns in clays from the Mississippi and from an area in Germany as well as in sediments in Australia, it was assumed that this unique pattern of dioxins was formed by geothermal processes over time from organic material and chlorine. Later, novel evidence [40] was provided based on congener-specific carbon-isotope analysis of OCDD in ball clays from the USA and Japan. Elevated concentrations of OCDD were isotopically distinguished from the anthropogenic source materials (fly ash and pentachlorophenol) and environmental samples (sediment and soil). The isotopic signatures and the occurrence of OCDD in ancient ball clays deposited in the Tertiary Era provide evidence for the in situ formation of dioxins.

\subsubsection{Survey on Levels in Clays, Contamination of Feed and Change of Dioxin Pattern in Food of Animal Origin as Result of Bioaccumulation}

Kaolinic clays were used as a feed additive and according to EU regulations belonged to the functional group of binders, anticaking agents and coagulants. Up to $2 \%$ can be added to feed. As it became clear that contaminated clay had been sold to many other states, a lot of clay and feedstuff samples were analyzed. A possible transfer to food was also checked. Later, cosmetic products were included.

A wide range of dioxin levels was found in clay (e.g. levels between 64 and 479 ng WHO-TEQ/kg in four clay samples from the Westerwald area), however, many non-contaminated clay samples were also found showing that not all clay samples on the market were contaminated. As result of a study on transfer to food, the use of contaminated mineral feed (31.8 ng WHO-TEQ/kg) did not result in significantly increased levels in milk or veal, whereas use of clay as anticaking agent in poultry resulted in levels up to about $60 \mathrm{pg}$ WHO-TEQ/g fat in turkey. The difference was explained by low consumption rates of mineral feeds (contributing only to about $0.5 \%$ to $2 \%$ of the daily feed ration) in contrast to use as anticaking agent: In this case, if the possibly contaminated compound 
feed was used only as a feedstuff for a long period, it would contribute up to $100 \%$ of the intake [41].

Figure 10 shows the PCDD/PCDF pattern of a compound feed contaminated by use of kaolinic clay from the Westerwald area (9.6 ng WHO-TEQ/kg feed). The pattern is exactly the same as for "pure" kaolinic clay (e.g. the sample with $479 \mathrm{ng}$ WHO-TEQ $/ \mathrm{kg}$ ): By far highest concentration of OCDD, followed by HpCDD with lowering levels to TCDD; no PCDF.

Based on concentrations, the PCDD/PCDF pattern of meat of a turkey which was fed with this compound feed and contained high dioxin levels (63.6 pg WHO-TEQ/g lipid) looks different (Figure 11).

The transfer rates have to be taken into consideration, as explained for the transfer of dioxins from citrus pulp to milk (see chapter 2.1.1). Again, if the dioxin patterns is expressed as relative contribution to WHO-TEQs, the patterns of the feeding stuff (containing contaminated clay) and the meat of the turkey is quite comparable with TCDD and PeCDD dominating by far (Figure 12 and Figure 13) (all illustrations of results of study published as ref. [41]).

\subsubsection{Detective Work at a New Incident in 2004 Contaminating Food and Feed}

During a monitoring project on milk in The Netherlands in August 2004, a pooled milk sample was found to contain three times higher levels of PCDD/Fs than the background. The sample was composed of milk from three different milk collection trucks. One sample was identified containing $5 \mathrm{pg} \mathrm{TEQ} / \mathrm{g}$ fat. The three farms were visited and sampled, and again one milk sample showed elevated levels, then of $20 \mathrm{pg} \mathrm{TEQ} / \mathrm{g}$ fat. The pattern resembled that of contaminated clay taking into account the carry-over rates for different congeners from

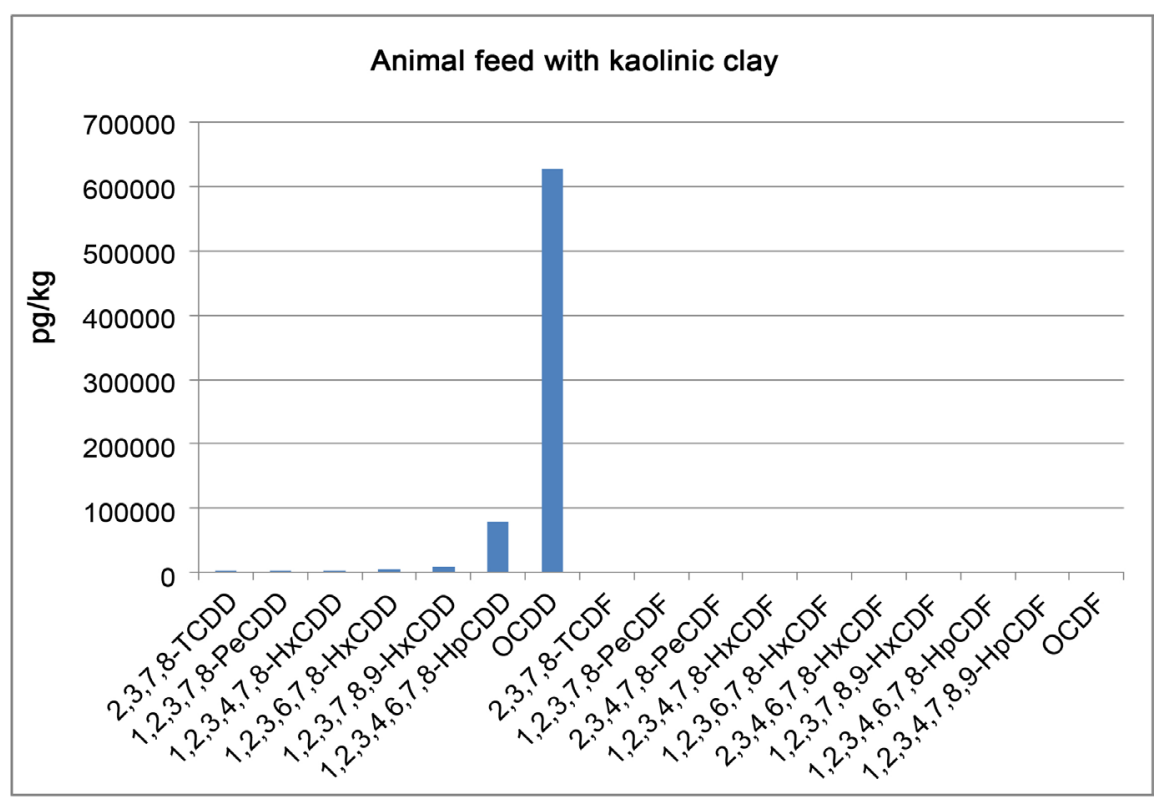

Figure 10. PCDD/PCDF pattern of a compound feed with elevated dioxin levels (9.6 ng WHO-TEQ $/ \mathrm{kg}$ ) contaminated by use of kaolinic clay (pattern the same as in "pure" dioxin-contaminated kaolinic clay). Concentrations of PCDD/PCDF congeners in $\mathrm{pg} / \mathrm{kg}$. 


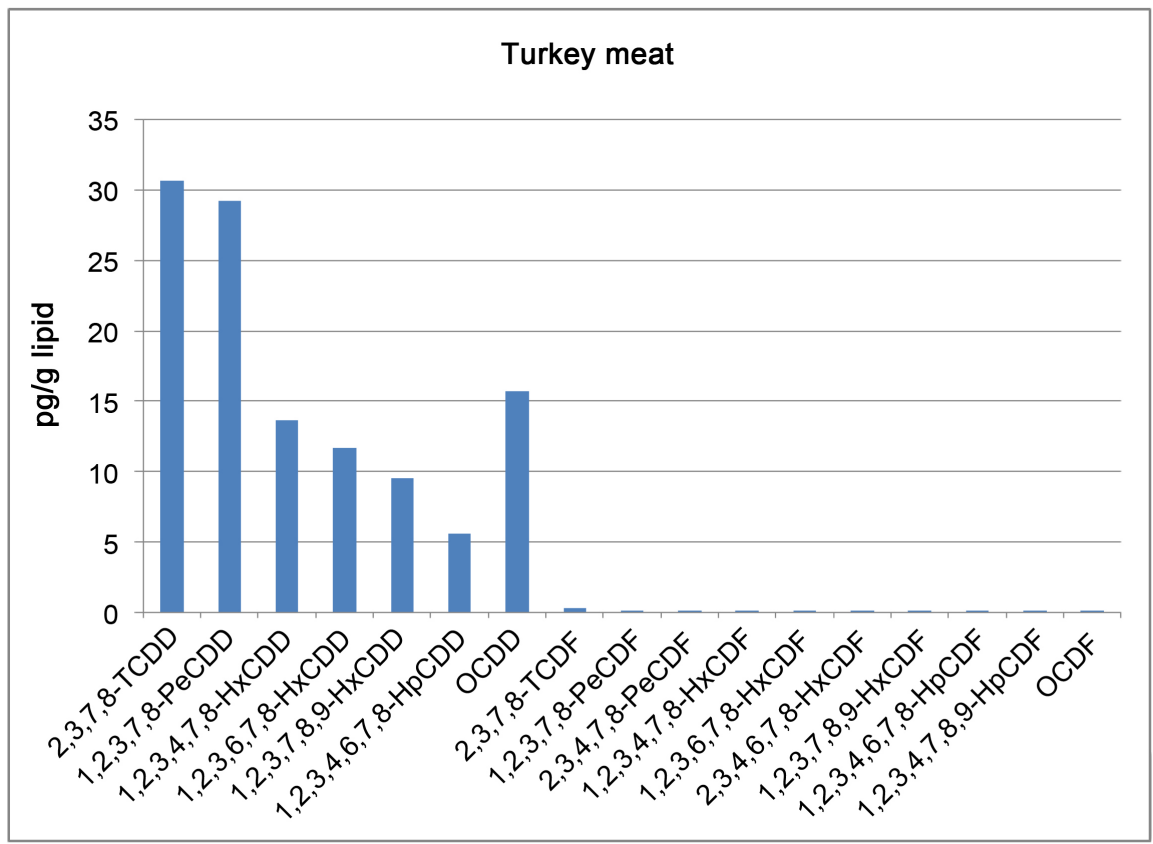

Figure 11. PCDD/PCDF pattern in meat of a turkey which was fed with contaminated compound feed and contained high dioxin levels (63.6 pg WHO-TEQ/g lipid). Concentrations of PCDD/PCDF congeners in pg/g lipid.

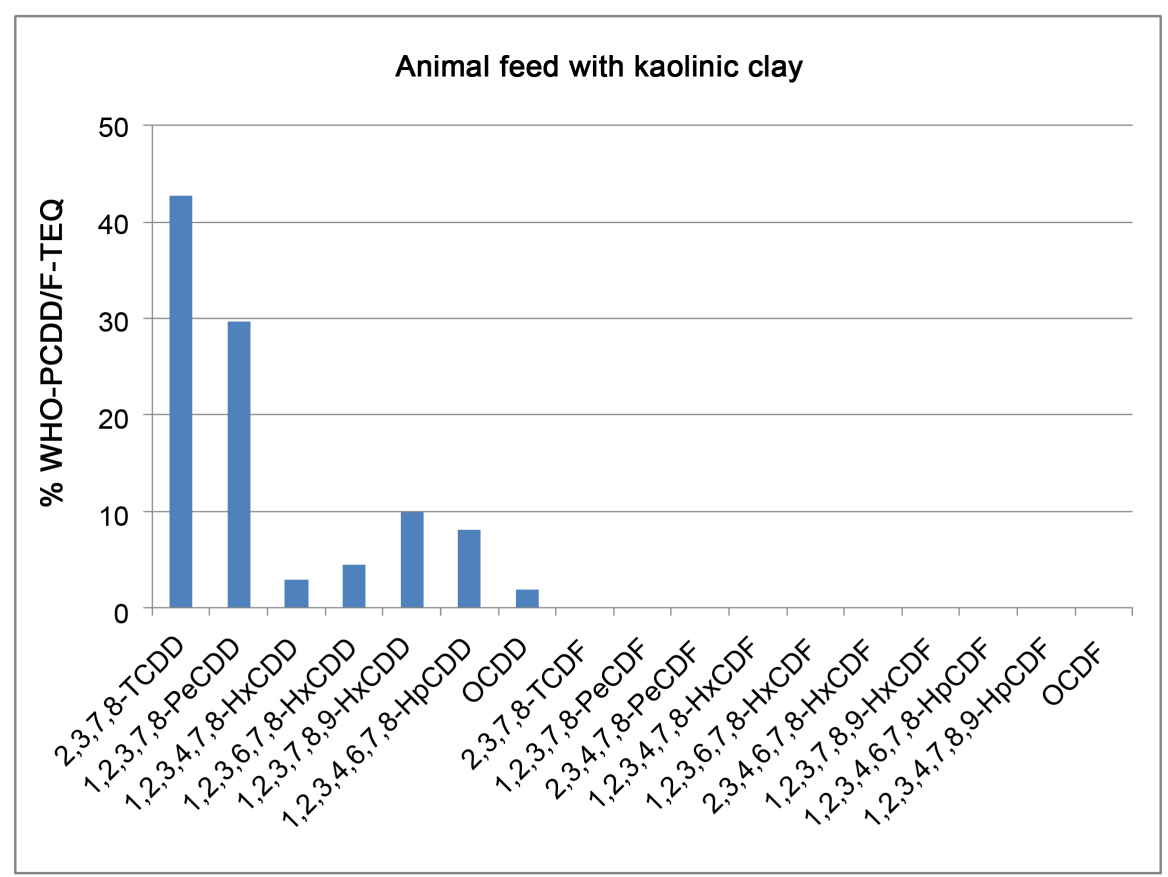

Figure 12. PCDD/PCDF pattern of a compound feed with elevated dioxin levels (9.6 ng WHO-TEQ $/ \mathrm{kg}$ ) contaminated by use of kaolinic clay, expressed as relative contribution to WHO-TEQ.

feed to milk.

Therefore, when the inspection service visited the farm, it was asked to look specifically for this material, however without success. All feed items were collected and screened with CALUX, revealing that in particular, potato peels 


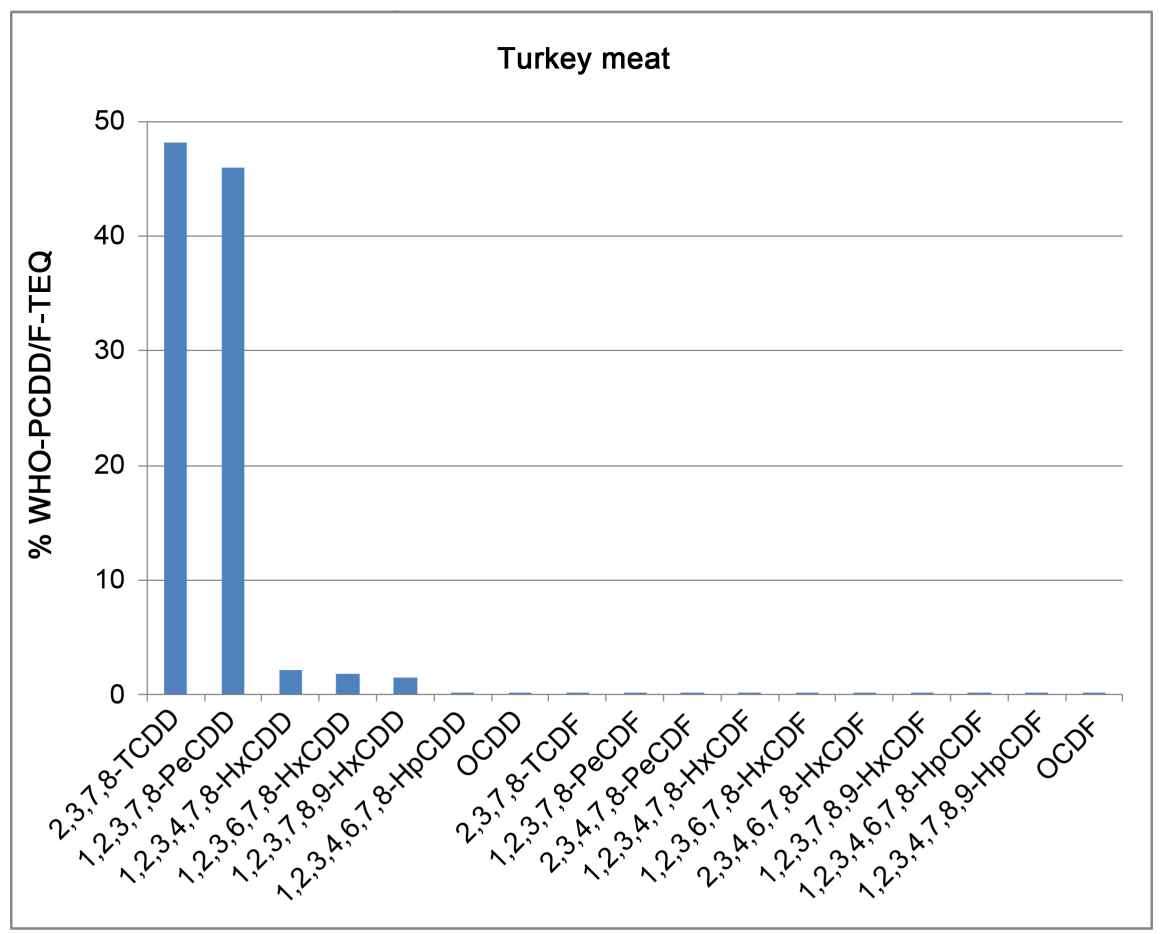

Figure 13. PCDD/PCDF pattern in meat of a turkey which was fed with contaminated compound feed and contained high dioxin levels (63.6 pg WHO-TEQ/g lipid), expressed as relative contribution to WHO-TEQ.

showed a clearly elevated response, high enough to account for the elevated milk levels. The potato peels were by-products from the wastewater treatment plant of a Dutch producer of French fries and other potato products. Levels amounted to $44 \mathrm{ng} \mathrm{TEQ} / \mathrm{kg}(88 \% \mathrm{dw})$. The farmer in question was one of the few to obtain this wet material that was fed to the cows at a ration of $20 \mathrm{~kg} /$ day ww or about 2 $\mathrm{kg} / \mathrm{day} \mathrm{dw}$. Initially it was unclear how the potato peels were contaminated but eventually it became evident that the company had recently changed its procedure for sorting out low density potatoes. Initially a salt bath was used for this purpose but for environmental reasons the producer had switched to a bath with different types of clay, including kaolinic clay. Analysis of a number of clay samples revealed levels around 1 to $2 \mu \mathrm{g} \mathrm{TEQ} / \mathrm{kg}$ with a pattern very similar to that in potato peels. The production process of the company was carefully analyzed in order to identify other products that could have been contaminated. Although, hundreds of farms were blocked as a precaution, only three milk farms showed clearly elevated dioxin levels [42] [43].

Surprisingly, the kaolinitic clay which had contaminated the potatoes came from Germany [44] and was produced in the same area which was found already in 1999 to have very high dioxin levels. After the 1999 incident it was assumed that this material would no longer be used in the feed and food chain-however, this was true for use as feed additive, but use for technical purposes such as replacement of salt in a water bath for sorting out low density potatoes was not considered. This again shows the complex real world of food production. 


\subsubsection{Geophagy (Consumption of Clays) and Elevated Dioxin Levels in Humans}

The intentional consumption of soil and clay materials by animals and also by humans is called geophagy. It is reported to be very common among other parts of the world in Africa. In traditional medicine, pregnant women consume clay as a cure against morning sickness but possibly also as a source of minerals like iron. In Africa, clays for oral use are collected in rural mines, dry river beds, termite nests and walls of housing but they can also be purchased at local markets, traditional remedy shops or even upmarket retail shops. Migrants from Africa, Asia and Suriname have introduced the practice of geophagy to Western societies. These clay products can be purchased in ethnic shops. Data from the literature suggests that intake levels are typically between 30 and $80 \mathrm{~g}$ per day. Knowing the problems of a possible high contamination of clays with dioxins, an investigation of so-called "pregnancy clays" for the presence of dioxins was started in the Netherlands. Some of the samples were highly contaminated [45].

For evaluation of possible consequences of consumption of such clays with high dioxin levels, congener patterns of PCDD/Fs in clay products were compared to those in mother milk samples collected in different African countries within the World Health Organization (WHO) program on human milk: Since 1987, WHO carried out global surveys on PCDDs, PCDFs and PCBsin human milk. After signing the Stockholm Convention on elimination of certain persistent organic pollutants (POPs), these surveys were jointly coordinated by WHO and the United Nations Environment Programme (UNEP) as contribution to the effectiveness evaluation. Results of the three most recent surveys from 2000 to 2012 allow the identification of global quantitative differences and provide baseline information for 69 countries. Individual human milk samples were collected following a WHO-designed procedure and combined to form a representative national pooled sample. Large global and regional differences were observed. Levels of PCDDs and PCDFs were highest in India and some European and African countries. In Africa, the widest variation in contamination was observed. Ethiopia, Kenyaand Uganda had the lowest levels of PCDDs and PCDFs, while Egypt, Côte d'Ivoire and the Democratic Republic of the Congo had the highest levels in these surveys (Figure 14) [46] [47].

Two different sources were discussed for the elevated levels in these African countries: In Egypt, the great majority of its over 80 million people lives near the banks of the Nile River, in an area of about 40,000 square kilometers, where the only arable land is found. On this relatively small area, industrial production sites and open burning of waste as possible emission sources and agricultural areas are close together. This might explain the findings of high levels of PCDD/ PCDFs. The furan-dominated pattern with particularly high contribution of PeCDF to the TEQ levels is an indicator for combustion processes as source for this contamination.

A completely different source is discussed for the relatively high levels in Côte d'Ivoire and Democratic Republic of Congo: Figure 15 shows the pattern (as 


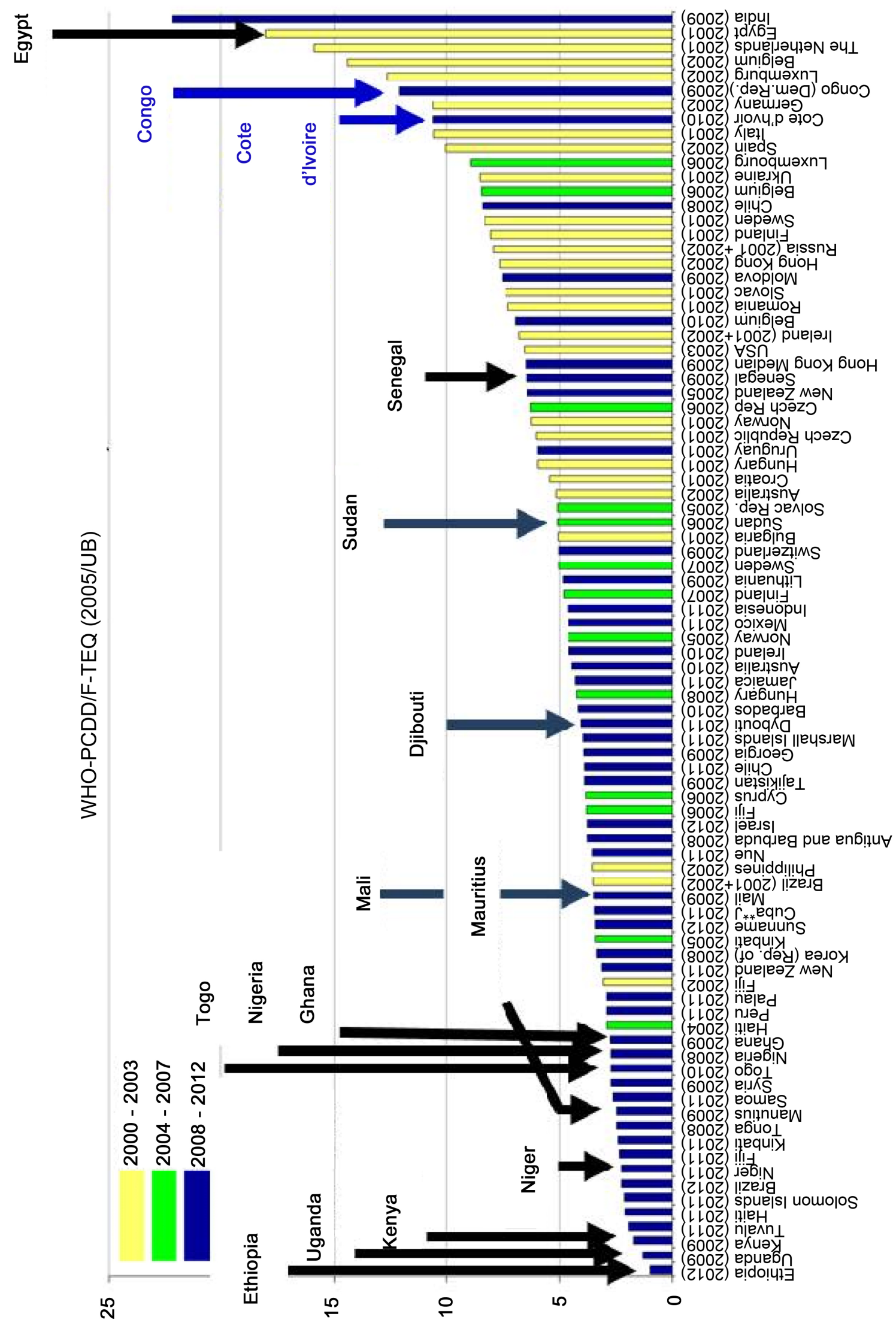

Figure 14. Levels of PCDD/PCDF in human milk: results of the WHO/UNEP-coordinated exposure study over the period 2000-2012 with indication of African countries. 


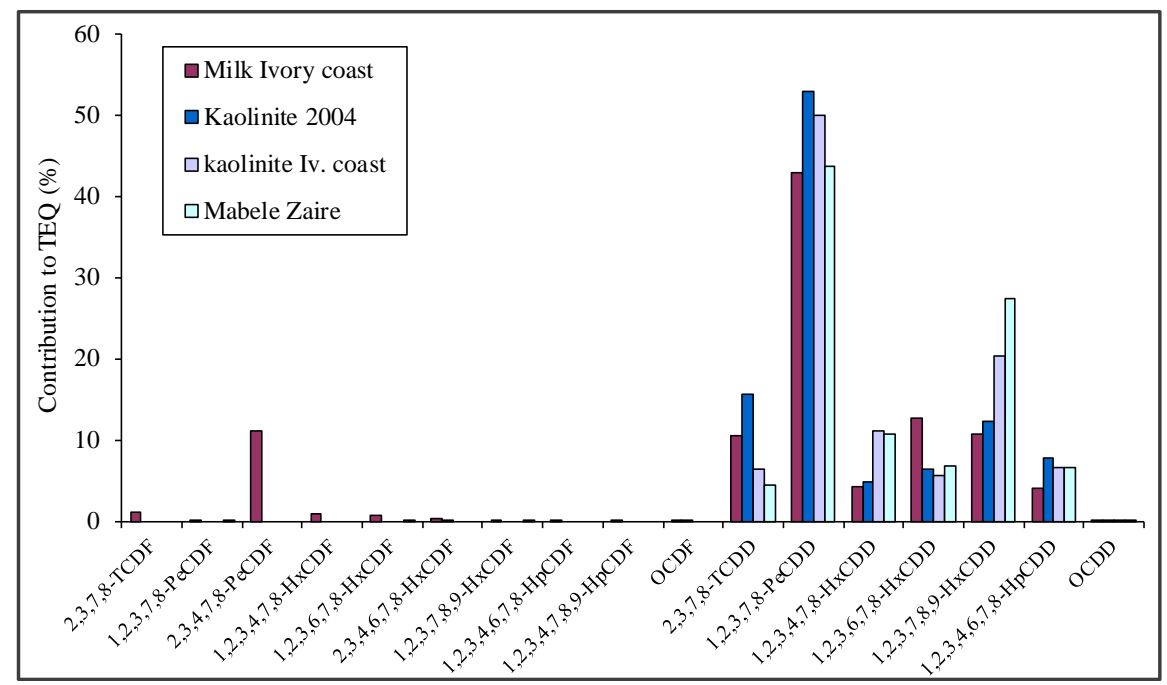

Figure 15. Comparison of the congener pattern in human milk from Côte d'Ivoire with the patterns observed in two Kaolinite and one Mabele clay samples (from ref. [49]).

relative contribution to TEQ) for human milk from Côte d'Ivoire in comparison with three different clays (kaolinic clay causing the 2004 incident in The Netherlands, a clay collected from Côte d'Ivoire and a Mabele clay from Democratic Republic of Congo) [48] [49] (illustration from ref. [49]). The patterns match to a high degree: The PCDD-dominated pattern in human milk concurs with the pattern found in clays and is to be expected after bioaccumulation. As conclusion, the relatively high levels and the similarity of the congener patterns to those from the clays strongly suggest that the use of clays during pregnancy contributes to these high levels in the human milk. Regarding the susceptibility of the developing fetus and young child to dioxins the use of contaminated clays should be avoided.

In one clay sold as dietary supplement for humans in Germany, CVUA Freiburg determined a level of $7130 \mathrm{pg}$ WHO-PCDD/F-TEQ/kg product. For evaluation of the toxicological risks with regard to human consumption, the Federal Institute for Risk Assessment (BfR) in Germany compared the intake resulting from $14.4 \mathrm{~g}$ per day (given by the producer as maximum recommended intake for this product) with the tolerable weekly dioxin intake (derived by the EU Scientific Committee on Food) and concluded that consumption of this clay alone would contribute to $86 \%$ of the tolerable intake. With the additional dioxin intake via food, the tolerable intake would be exceeded. It was concluded that a short-term intake would not cause a health concern; however, with regard to possible consequences of long-term consumption, dioxin-contaminated clay should not be used as dietary supplement [48].

\subsection{From Bioanalytical Screening to GC/MS Identification of the Source: Brominated Flame Retardants and Brominated Dioxins in Choline Chloride}

This example of a forensic examination shows the complex work from first findings of elevated dioxin levels in bioanalytical screening via comprehensive 
physicochemical investigations to the identification of brominated contaminants [50] [51]. So far, it is the only known case where brominated dioxins could be identified as reason for elevated TEQ levels and brominated flame retardants as source of the contamination.

In 2008, tests of samples of the feed additive choline chloride were performed by RIKILT in the Netherlands showing an elevated response in the DR CALUX assay. Comparison with the response of spiked feed samples indicated initially levels of 5 - $6 \mathrm{ng}$ TEQ $/ \mathrm{kg}$. Finally, 26 samples were analyzed in 2008 of which 10 showed a response indicating a level higher than $1 \mathrm{ng}$ bioanalytical equivalents (BEQ) $/ \mathrm{kg}$. The highest observed level was $11 \mathrm{ng} B E Q / \mathrm{kg}$. However, GC/MS analysis could not confirm the presence of PCDD/PCDFs or dioxin-like PCBs.

RIKILT selected two samples with indicative BEQ levels of 1.2 and $4.9 \mathrm{ng}$ $\mathrm{BEQ} / \mathrm{kg}$ respectively for further examination by GCxGC-TOFMS. As are sult, brominated flame retardants (BFRs) were identified: Levels of up to $150 \mathrm{ng} / \mathrm{kg}$ were found for a number of poly brominated diphenylethers (PBDEs) and up to $3600 \mathrm{ng} / \mathrm{kg}$ for 2,4,6-tribromophenol.

Furthermore, an unknown peak was observed with a molecular mass of 868 . The fragmentation indicated the presence of eight bromines. Searching on the internet indicated that this compound could be a new brominated flame retardant, named FR-1808 or Octabromo-1,3,3-trimethylphenyl-1-indan (OBIND) (Figure 16). A standard was ordered and the identity of the compound was confirmed. Estimated levels of two samples were 140 and $700 \mathrm{ng} / \mathrm{kg}$ respectively. OBIND was tested in the CALUX assay, but showed no response.

The levels of the BFRs were in line with the differences in response of the two samples in the CALUX-assay, but these compounds could not explain the elevated BEQ response. Therefore, subsequent research focused on the possible presence of brominated dioxins in the two samples. This was performed at the EU Reference Laboratory for Dioxins and PCBs in Feed and Food. Several tetraand pent a brominated dioxins and furans could be detected, with 2,3,7,8-TBDF being the most important congener. These data confirm that brominated dioxins could at least be partly responsible for the observed response in the bioassay. When applying the same TEFs as for the chlorinated dioxins, levels amounted to

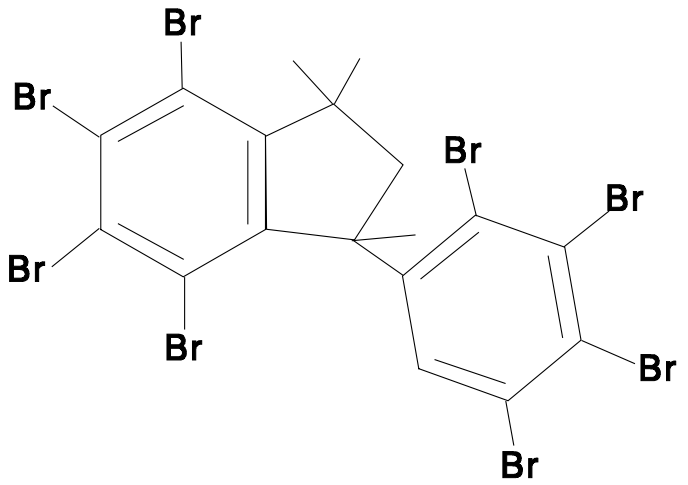

Figure 16. Structure of octabromo-1,3,3-trimethylphenyl-1-indan (OBIND). 
51 and $513 \mathrm{pg}$ TEQ/kg respectively. This is lower than the estimated levels from the bioassay response. However, the response of the different congeners may be different to the TEF values and furthermore, not all congeners were analyzed.

This case shows that the follow-up of well validated "false-positive" samples in the CALUX bioassay by comprehensive analyses (in particular with GCTOFMS) may actually result in the detection of novel emerging risks, in this case the presence of brominated flame retardants and brominated dioxins in a widely used feed additive. This included a novel BFR, OBIND, that was not detected in feed or food before.

It must be stressed that the bioanalytical screening result has to be well validated, so as not to promote any unconfirmed (by confirmatory HRMS) elevated result as arising from a novel contaminant. There are a number of factors which can cause apparently elevated results in screening methods. These factors were carefully controlled by RIKILT before the conclusion was drawn to check for brominated contaminants.

Although the levels observed in this case may not directly present a risk for the animals and the consumers, it was evident that during the production or handling of this material it became contaminated with industrial chemicals whose introduction in the food chain was highly undesirable.

\subsection{Buffalo Milk Contamination in Italy ("Mozzarella Incident")}

A significant part of the mozzarella samples of the Campania Region (Italy) collected during a monitoring program performed in 2007/2008 proved to be noncompliant with EU regulation for dioxins and dioxin-like PCBs. This semi-soft cheese with a protected origin designation from the European Union was made of buffalo milk. Reportedly 33,000 tons were produced annually, of which most is consumed in Italy, but parts exported, mostly to European countries but also to Japan, Korea and Russia. The production of the contaminated mozzarella was confined to a limited area of the region. Accusations were made that illegal deposition of toxic waste caused the problems. The contemporaneous crisis of the household waste disposal in Naples and its worldwide broadcast and impact on public opinion put the mozzarella cheese under a possible "dioxin" concern.

This case should not illustrate the detective work to identify the source but the risk management approach-the development of a strategy to perform a comprehensive monitoring programme in short time: In order to warrant the safety of the food products (in particular mozzarella), the European Commission asked the Italian government to adopt an extraordinary monitoring plan, to be applied to the entire region. Results were required to be provided within one month, as a preventive measure to limit a further export ban on the product, as already imposed by South Korea and Japan. With emergency assistance from the EU Reference Laboratory, a list was provided to Italy comprising laboratories which could offer several hundred analyses per week either as confirmatory methods or as screening methods.

On this basis, the required comprehensive control program could be per- 
formed in Italy. With regard to unanswered questions related to the source of contamination, the Italian authorities chose a strategy to analyze for dioxins and for dioxin-like PCBs separately and to take the EU-action limits (2 pg WHO$\mathrm{PCDD} / \mathrm{F}-\mathrm{TEQ} / \mathrm{g}$ fat and $2 \mathrm{pg}$ WHO-PCB-TEQ/g fat) as reference point to decide on acceptability of the samples. The Commission accepted this approach.

As a significant number of samples was expected to exceed the action levels, Italy decided not to use screening methods but to have the samples analyzed by confirmatory methods: Italy chose these services in order to avoid delays by confirmation of samples which otherwise could have been pre-analyzed with bioassay screening methods which would have required confirmation by HRMS after screening positive. This requires additional organization (shipment of an additional aliquot to the confirmatory laboratory), time (for confirmation) and costs. Therefore, only laboratories performing confirmatory methods and offering a high sample throughput within one week were selected [52]. 460 samples of buffalo milk collected in the province of Caserta (Italy) had dioxin levels between 0.17 and $87 \mathrm{pg}$ WHO-PCDD/PCDF-TEQ/g lipid with a median value of $2.25 \mathrm{pg}$ WHO-PCDD/PCDF-TEQ/g lipid [53].

\subsection{PCBs and Dioxins in Pork in Ireland}

\subsubsection{From Initial Findings to Identification of the Source}

During routine monitoring by the Irish authorities of the food chain for a range of contaminants, in November 2008 elevated levels of polychlorinated biphenyls (PCBs) were found in a pork fat sample. In order to identify the source of the contamination, further porcine fat tissue samples and also animal feed ingredients (pot ale syrup, soya oil, soya meal, soyahulls, feed minerals, barley, dried breadcrumbs and wheat) from the identified pig farm were analyzed. Simultaneously, as the elevated PCB levels were seen as an indicator for an unacceptable dioxin contamination, further investigations were started to determine the dioxin content.

Elevated levels of six marker PCBs were confirmed in the porcine fat samples and found in dried breadcrumb. All other feed components did not contain detectable levels of PCBs. The contaminated bread crumbs were produced by a feed recycling plant, and a full investigation into the manufacture and distribution of this feed was undertaken. The plant produced feed via the recycling of waste bread and waste dough delivered on-site from various bread factories. The process was based on a convection drying system, in which combustion gas was used as the drying medium, there by coming in direct contact with the material to be dried.

Examination of the production process revealed that the fuel oil used to produce the drying gas was the cause of the contamination. Analysis of individual samples of ingoing raw feed material sampled prior to the drying process confirmed this conclusion, as none of these samples was found to be contaminated. It was therefore concluded that contamination must have taken place during the drying process and was due to airborne deposition and consequent adsorption of 
contaminants contained in the exhaust gas onto the surface of the feed material. Subsequent analysis of the fuel oil confirmed a very high contamination level of PCBs, the congener pattern of which indicated a commercial PCB mixture to be the likely source of the contamination [54] [55].

At the same time, private food-quality systems detected this dioxin incident: A French meat processor detected the contamination of pork with high levels of dioxins (433 pg WHO-PCDD/PCDF-TEQ/g fat). The tested product was received from a meat-production company in the Netherlands which got supplies from several countries. The detective work for tracing and tracking of the source and the performance of a comprehensive private surveillance program is described in detail [56]. First positive test results from samples from the Republic of Ireland were received in early December. The private programme was stopped following the positive results from Irish origin and the announcement of a full recall of pork produced in Ireland by the competent Irish authorities.

\subsubsection{Source of the Contamination and Congener Patterns}

Fuel oil samples were initially analyzed for indicator PCBs by the Irish Pesticide Control Service Laboratory. Further samples were taken by the Irish Environmental Protection Agency (EPA) and sent for full dioxin analysis as part of their investigation into potentially illegal disposal of PCBs. The samples were found to contain elevated levels of PCBs (approximately $380 \mathrm{mg} / \mathrm{kg}$ for the sum of the indicator PCBs plus dioxin-like PCBs) of the Aroclor 1260-type. The total dioxin and furan composition of the oils was in the range of $800 \mathrm{ng} I-\mathrm{TEQ} / \mathrm{kg}$. As a result, the fuel was not fit for the purpose [57].

The fuel oil was recycled oil which was supplied from Northern Ireland. Whilst the fuel used was understood to have been waste oil, it is not suggested that the feed operator knowingly purchased the fuel as waste oil. No further comment could be made by the Irish EPA as to the origin of the source of the fuel or the circumstances under which the fuel was supplied and the origin of the $\mathrm{PCB} /$ dioxin contamination as this was subject to a criminal investigation [see [57]].

The PCB patterns of the fuel oil, the contaminated dried crumbs and three contaminated meat samples are very similar (Figure 17 from ref. 56; for comparison also fat from an incident at a gelatin plant in Belgium is included.).

In terms of contribution to the TEQ level in contaminated pig meat and fat, $2,3,4,7,8-\mathrm{PeCDF}$ was by far the most important congener (about $85 \%-90 \%$ ). The samples contained also elevated dl-PCBs, contributing about $3 \%-5 \%$ to the total TEQ levels. The patterns of three meat samples and bread crumbs for PCDD/PCDF and dl-PCB are shown in Figure 18 (from ref. [56]; again with fat from the incident in a gelatin plant in Belgium). In the meat samples, the ratio between the sum of the seven indicator PCBs and the dioxin TEQ varied between 2000 and 4000, being much lower than the ratio of 50,000 observed during the Belgian dioxin and PCB incident, whereas in bread crumbs the ratio was only 166 . In the oil, the relative amount of PCDD/PCDFs was much lower than in the bread crumbs (ratio indicator PCBs: TEQ $>14,000$ ) indicating that most of 


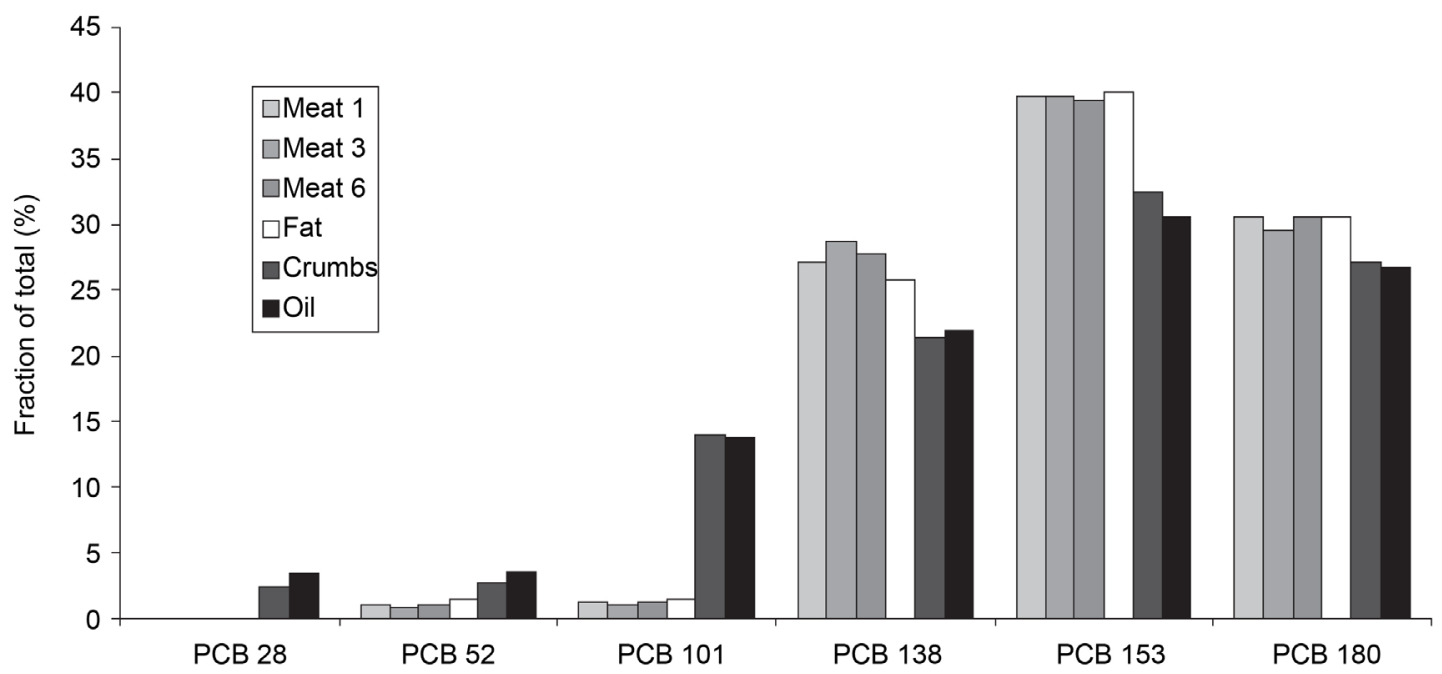

Figure 17. Patterns of indicator PCBs in three meat samples, the bread crumbs and a sample of oil used for the drying process (from ref. [56]).
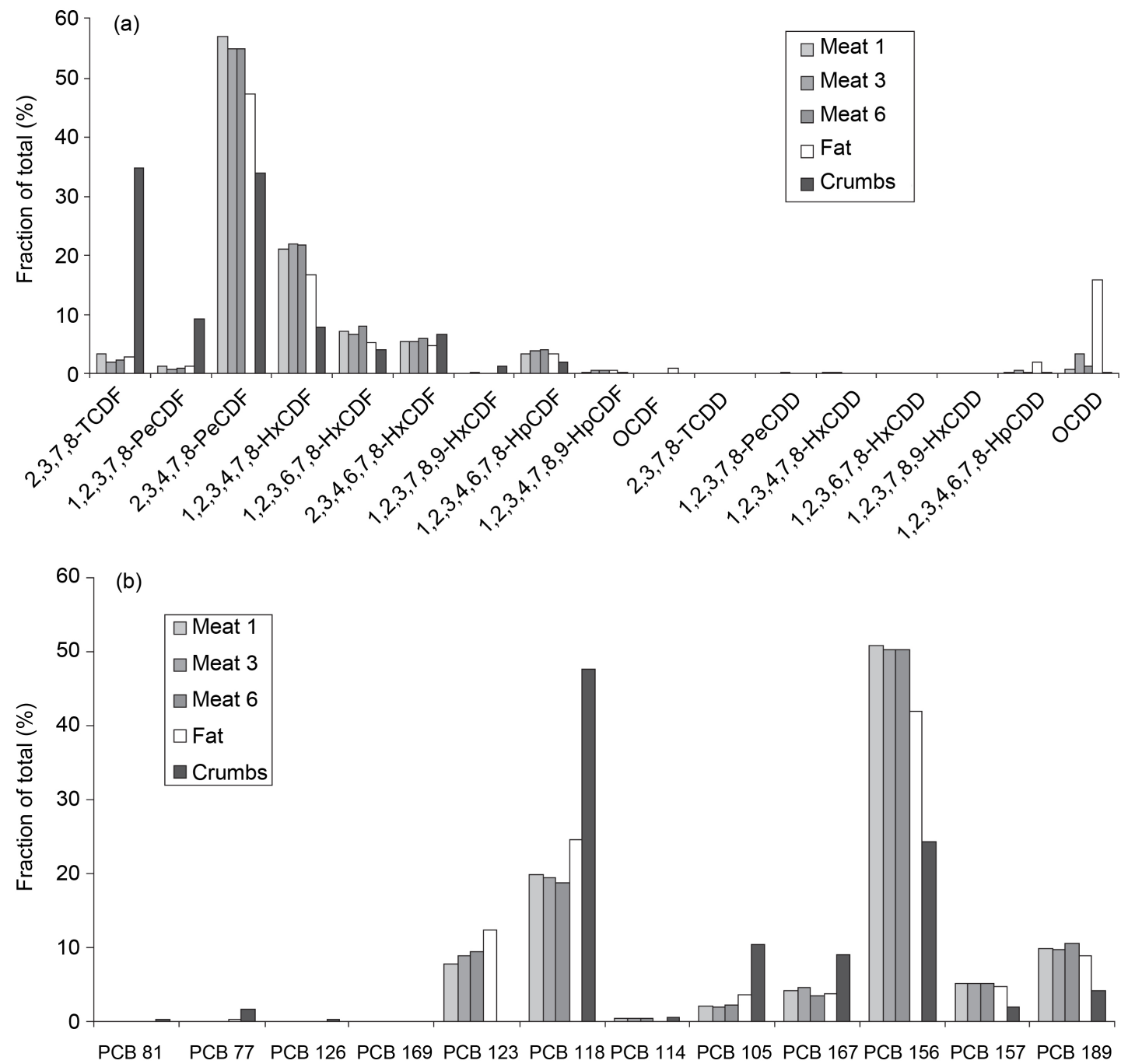

Figure 18. Patterns of PCDD/PCDF and dioxin-like PCBs in three meat samples and bread crumbs (from ref. [56]). 
the dioxins may have been formed during the burning of the oil resulting in transformation of the PCBs in the oil [56].

\subsubsection{Risk Assessment}

On 8 December 2008, the European Commission requested urgent scientific advice from the European Food Safety Authority (EFSA) on the risks to public health due to the contamination by dioxins in pork from Ireland. As basis for the evaluation, levels of dioxins and dioxin-like PCBs of up to $200 \mathrm{pg}$ WHO-TEQ/g fat as reported until the time of request were used. EFSA calculated several exposure scenarios for both average and high consumers assuming three different dioxin concentrations in the pork $(50,100,200 \mathrm{pg}$ WHO-TEQ/g fat), and three different proportions of contaminated meat (100\%, $10 \%$ and $1 \%)$.

On 10 December 2008, the statement of EFSA was published. In very extreme cases, assuming a daily consumption of $100 \%$ contaminated Irish pork, for a high consumer of pork fat during the respective period of the incidence (90 days), at the highest recorded concentration of dioxins (200 pg WHO-TEQ/g fat), a considerable erosion of the uncertainty factor embedded in the tolerable weekly intake (TWI) was concluded. Given that the TWI has a 10-fold built-in uncertainty factor, this unlikely scenario would reduce protection, but not necessarily lead to adverse health effects.

In a more likely scenario with a daily consumption of $10 \%$ contaminated Irish pork for a mean consumer of highest contaminated pork fat (200 pg WHO$\mathrm{TEQ} / \mathrm{g}$ fat) for the period of the incidence (90 days), the body burden would increase by approximately $10 \%$. EFSA considered this increase in body burden of no concern for this single event [58].

Based on reports that at least 10 pig farms were affected representing $8 \%$ of the total pig production in Ireland [see [54]], the assumption that $10 \%$ of the pork was contaminated seems realistic. However, the levels of up to $200 \mathrm{pg}$ $\mathrm{TEQ} / \mathrm{g}$ lipid were a clear underestimation with regard to a level of $433 \mathrm{pg} \mathrm{TEQ} / \mathrm{g}$ found by self-control of meat producers [see [56]].

The highest levels were found in samples from Poland: The Polish National Reference Laboratory (NRL) found extremely high levels of dioxins in bacon and pork liver originating from Ireland and asked the EU Reference Laboratory for urgent confirmation. A level of $466 \mathrm{pg}$ WHO-PCDD/PCDF-TEQ/g lipid was confirmed in pig meat and of $16,400 \mathrm{pg}$ WHO-PCDD/PCDF-TEQ/g lipid in pork liver [59].

The potential effect of a peak exposure resulting from the consumption of a highly contaminated food product was not covered in the EFSA assessment. Considerations of a peak exposure in comparison to the equilibrium between adipose tissue and blood led to the conclusion that these concentrations of dioxins may cause an increased level in the blood and as a result, the temporarily increased exposure of sensitive tissues. This may be particularly relevant for in utero exposure for an unborn fetus. A re-evaluation was required to evaluate the risk of incidental high exposure. At that stage it seemed wise to declare that in 
the future such high levels are a clear food safety risk and to avoid such high exposures by adequate control of feed and food [56].

Exposure estimates derived for both dioxins and PCBs showed that the body burden of the general population remained largely unaffected by the contamination incident and only approximately $10 \%$ were exposed to elevated levels of dioxins and PCBs. Whilst this proportion of the population experienced quite a significant additional load to the existing body burden, the estimated exposure values do not suggest that these would be associated with adverse health effects, based on current knowledge [60].

\subsubsection{Risk Management and Economic Consequences}

The PCB contamination of meat was discovered in November 2008, followed by the detection of PCBs in bread crumb used as feed material as source of the incident. As an immediate precautionary measure, all farms known to have received feed from this mill were put under restriction [54].

Laboratory results confirming the presence of dioxins in pork fat of toxicological concern were received by the competent Irish authorities on 6 December 2008. Ten major pig farms and 38 cattle farms in Ireland and some farms in Northern Ireland were affected by the contamination incident. Pigs from these 10 farms, accounting for approximately $8 \%$ of the national pig output, were sent to one of ten pork processing plants, which collectively account for approximately $98 \%$ of the entire national pork product output, amounting to 150,000 tons of pork products per year. Due to the nature of pork processing, with pigs being slaughtered and processed on a weekly and in some cases daily basis from the same producers, and a considerable amount going into comminuted products, it was impossible to trace back final consumer products to the original pig suppliers, especially produce manufactured months before. Therefore, as a precautionary measure, the Irish authorities decided on Saturday 6 December to require a total recall of all Irish pork and pork products produced from pigs slaughtered in Ireland between 1September and 6 December 2008 from the market-the biggest food recall to date in Ireland [61] [62].

Based on the conclusions of the EFSA statement, the EC issued guidelines, on 10 December 2008 for the management of the Irish contamination incident to ensure that potentially highly contaminated products were quickly removed from the market for the protection of public health. These guidelines aimed also at ensuring a harmonized enforcement approach at EU level [63].

Internationally, a total of 22 countries were identified to have received implicated Irish pork and were shown to further distribute or even deliver back to Ireland produce originating in Ireland [62]. Figure 19 illustrates the extent of this food crisis and the difficulties of a total recall of all Irish pork [64]:

The complexity of the international trade in Irish pork is illustrated with the import of Germany (Figure 20) and the export from Germany (Figure 21) (both figures from ref. [64]).

As beef products were implicated to a much lesser extent, no consumer recall 


\section{Distribution/Recall is Simple...}

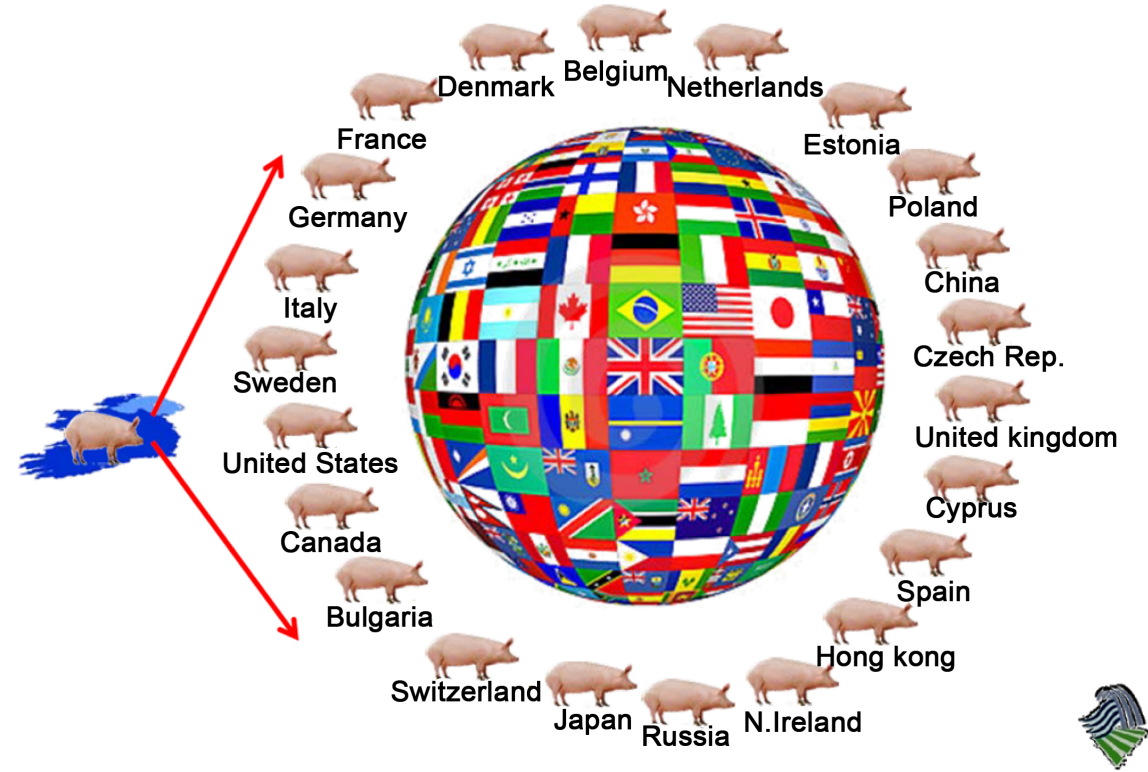

Figure 19. World-wide distribution of Irish pork (from ref. [64]).

\section{Where Did Germany Get Irish Pork?}

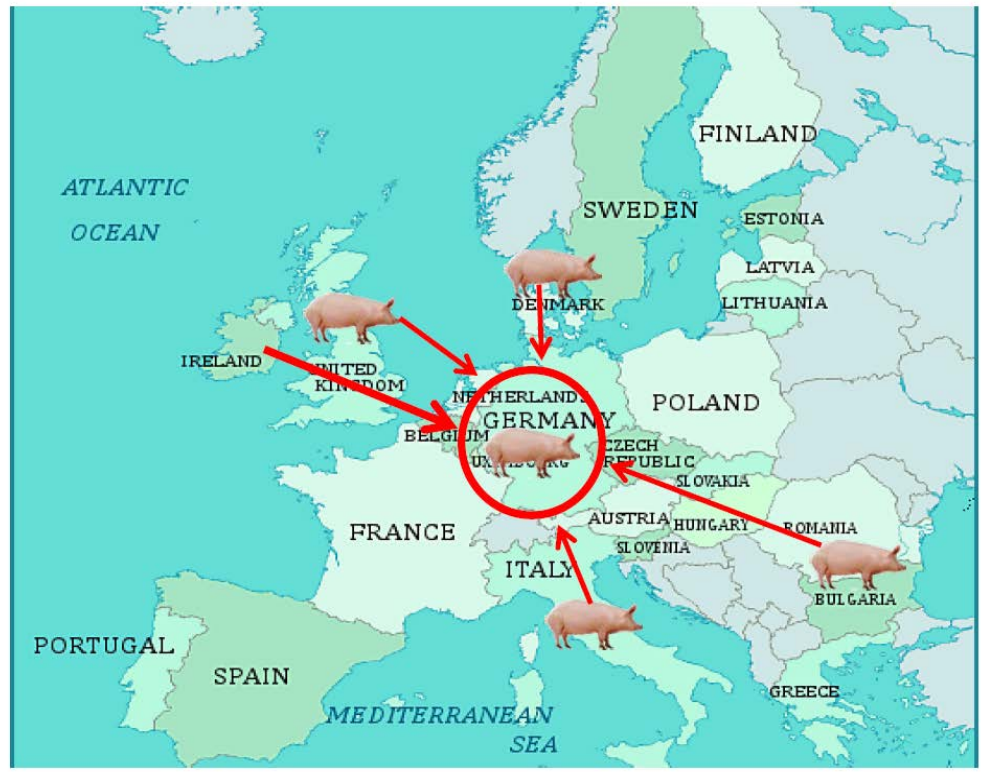

Figure 20. Import of pork from Ireland to Germany (from ref. [64]).

was necessary. Processing of cattle occurs less frequently and products are generally traded in cuts, hence beef products are fully traceable and all carcasses and cuts from implicated farms were withdrawn from the market [62].

30,000 tonnes of returned pork products were destroyed, as well as 170,000 pigs and 5700 cattle [57]. The Irish Government provided $€ 182,000,000$ as an 
Where Did Germany Export Irish Pork?

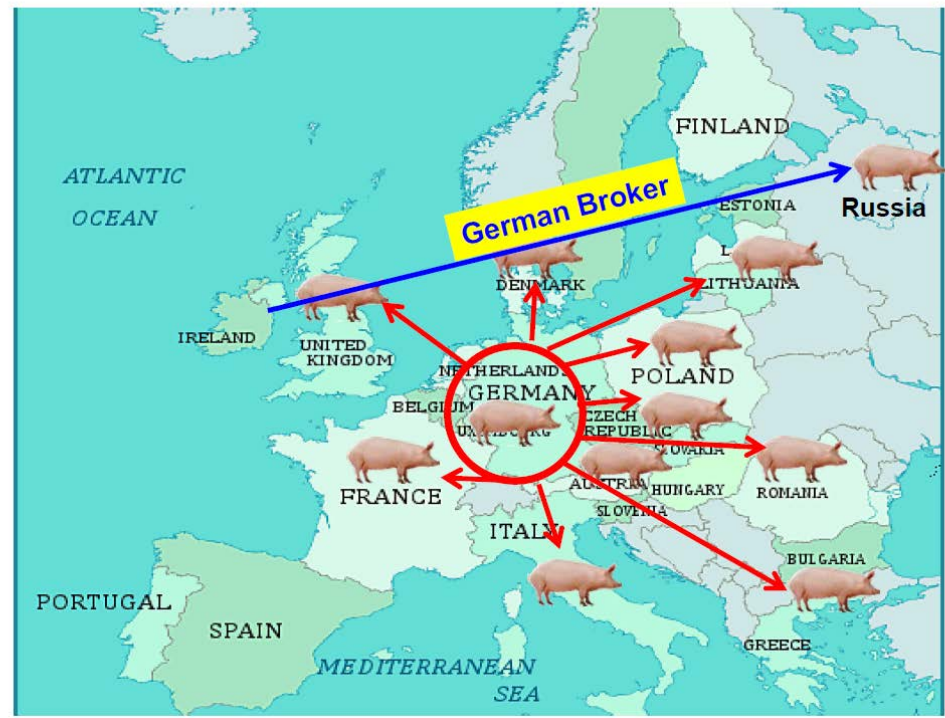

Figure 21. Export of Irish pork from Germany to other countries (from ref. [64]).

industry support measure, however, the total economic burden of the crisis was yet unknown in 2009. As direct economic consequences, pig farmers were facing financial ruin, 1800 pig processors were laid off as a result of the pork recall and another 10,000 indirect jobs were at threat. Many companies in Ireland lost their status as sole suppliers of pork to overseas markets and Ireland's reputation as "clean" food supplier came under threat [62]. With regard to the huge economic consequences, this was seen as largest dioxin incident in Europe since the Belgian dioxin crisis in 1998.

\subsection{German Dioxin Incident-Contamination of Fatty Acids Produced by a Biodiesel Company}

This incident was discovered shortly before Christmas 2010 and caused intense investigations over the period Christmas-New Year [65] [66] [67]: On 23 December 2010, the competent authorities of the German Federal State Lower Saxony were informed of elevated dioxin findings as a result of self-control analyses of a producer of feed for laying hens. Following communication between the Federal States, on 25 December 2010 North-Rhine Westphalia blocked the delivery of eggs from two farms which had received the contaminated feed. On 27 December 2010, the German authorities informed the European Commission's Rapid Alert System for Food and Feed (RASFF) that one feed fat producing company received a batch of fatty acids, which was meant to be used for technical purposes, had however got mixed with fat for the production of feed. These fatty acids were contaminated with dioxins.

The batch of fatty acids for technical purposes originated from a biodiesel company in Germany. In Germany, about 150,000 t waste edible fat are collected 
and used for production of biodiesel. After filtration of the mixed fat through saw dust, triglycerides and free fatty acids are separated by distillation $\left(250^{\circ} \mathrm{C}, 4\right.$ mbar). Triglycerides are used for production of biodiesel, whereas the separated fatty acids can be used for several technical purposes. The economic incentive to use fatty acids produced for technical purposes as fatty acids for production of feed is the difference between costs of about $500 €$ for technical fatty acids and about $1000 €$ for fatty acids suitable for feed production. Thus, a "re-declaration" of $20 \mathrm{t}$ fatty acids in a road tanker allows a profit of $10,000 €$ [see [67]].

Several other batches of fatty acids delivered to the feed fat producer in the second half of November 2010 were found to be contaminated, as well. Thus, the feed fat producer obviously had used fatty acids which were intended for the production of biodiesel from waste edible fat. Four retained samples of the period mid until end November had very high dioxin levels between 123 and 150 ng TEQ/kg. By way of precaution, all feed fat produced at the feed fat company from 12 November 2010 onwards was considered to be potentially contaminated. The potentially contaminated feed fat $(2256 \mathrm{t}$ ) was delivered to $25 \mathrm{com}$ pound feed manufacturers in Germany. Assuming 1\% - 3\% fat mixed into feed, about $70.000-220.000 \mathrm{t}$ feed might have been contaminated. There were no deliveries of potentially contaminated feed fat outside Germany.

Compound feed produced with the potentially contaminated feed fat was delivered to laying hen, fattening poultry (broilers and turkey), pig, dairy cattle, bovine, rabbit and goose farms, nearly exclusively in Germany. Farms having received potentially contaminated feed were blocked by way of strict precaution pending the outcome of dioxin analysis. There were initially 4760 potentially affected farms in Germany causing a major crisis and a temporary ban of eggs, meat from poultry or pig meat from Germany in several countries.

Of 230 samples from eggs from blocked farms analyzed, 195 samples were compliant with EU legislation. The highest level found in eggs produced with contaminated feed was $12 \mathrm{pg}$ WHO-PCDD/F-TEQ/g fat (EUmaximum level: $3.0 \mathrm{pg} / \mathrm{g}$ fat) and in poultry meat (meat of laying hens) $4.99 \mathrm{pg}$ WHO-PCDD/ F-TEQ/g fat (EU maximum level: $2.0 \mathrm{pg} / \mathrm{gfat}$ ). An overview of the available analytical results on food of animal origin from blocked farms (situation 23/02/ 2011) showed that 672 of 687 meat and milk samples did not exceed the maximum level [66].

The dioxin pattern was dominated by PCDD, with HexaCDD, HeptaCDD and OCDD being the predominant homologues (Figure 22, from ref. [68]). The main TEQ contribution came from 1,2,3,6,7,8-HexaCDD (ca. 50\%), 1,2,3,7,8,9HexaCDD (ca. 22\%), HeptaCDD (ca. 15\%) and 1,2,3,78,-PentaCDD (ca. 11\%). The HeptaCDF pattern with 1,2,3,4,6,8,9-HeptaCDF and 1,2,3,4,6,7,8-HeptaCDF was seen as fingerprint for PCP (and other highly chlorinated chlorophenol mixtures). The condensation of 2,3,4,6-TetraCP and PCP was discussed as an explanation for the observed pattern; lower chlorinated phenols were not significantly involved. Sources could have been 1) application of chlorophenols and pesticides, 2) production of biodiesel crops on PCDD/PCDF-contaminated sites, 


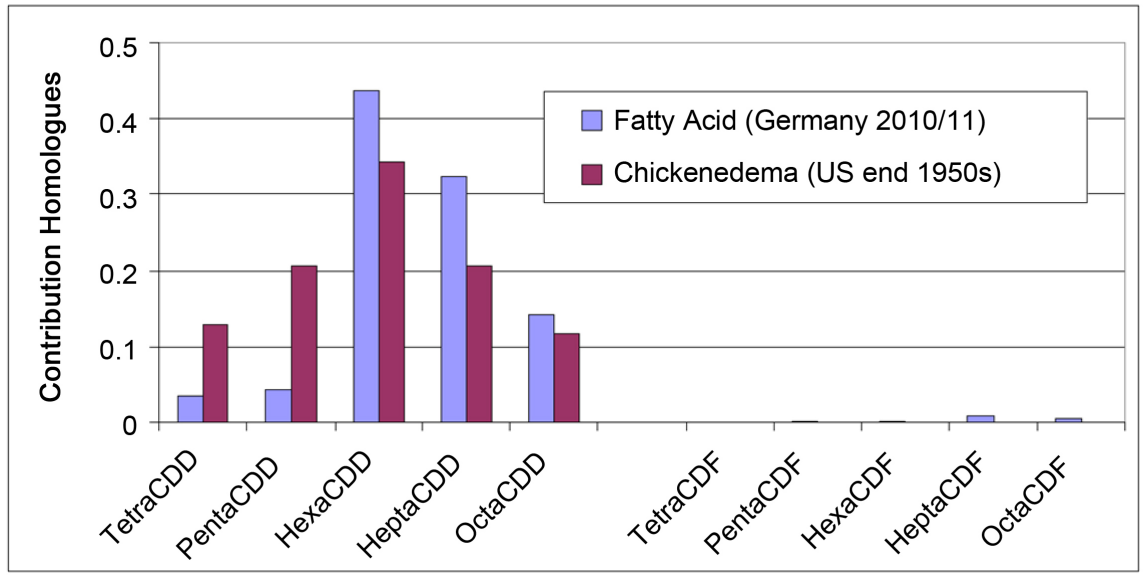

Figure 22. Homologue pattern in the contaminated fatty acid from biodiesel in comparison to the homologue pattern of the chicken edema case (US, 1950/60) (from ref. [68]).

3) PCDD/PCDF present in other additives. Furthermore, the modification of the pattern during the biodiesel production process was considered [68].

The characteristic pattern of four PCDD congeners was unknown, but were helpful for the detective work: It ran like a common thread from the fatty acids via the produced feed to the eggs and meat samples. The remaining question was how exactly the fatty acids were contaminated. Two hypotheses were discussed: the discharge of chlorophenol waste into waste edible fat or the filtration of waste edible fat using saw dust originating from waste wood treated with chlorophenols. A final answer could not be found, as there were no retain samples of the fatty acids intended for technical use [67]. The retention periods of samples for technical purposes are much shorter than for food or feed production putting an end to the detective work ends with the lack of availability of appropriate samples for further follow-up.

\section{EU Strategy-Maximum Levels and Action Levels for Feed and Food}

In 2001, the European Community developed a strategy for dioxins, furans and PCBs for a better protection of human health and of the environment from the effects of dioxins and PCBs [69]. The integrated and systematic approach is based on two pillars: 1) reduction of the presence of dioxins and PCBs in the environment; 2) reduction of the presence of dioxins and PCBs in feed and food. These legislative measures comprise the establishment of maximum levels at a strict but feasible level in food and feed and the establishment of action levels acting as a tool for "early warning" of higher than desirable levels of dioxins in food or feed.

Comprehensive background information on the EU strategy for PCDD/F and PCB and legislative measures concerning feed and food is summarized in ref. [2]. As legal basis, Commission Regulation (EC) No 1881/2006 determines that foods shall not be placed on the market when they contain a contaminant at a concentration exceeding the maximum level. Maximum levels are based on 
WHO-PCDD/F-TEQ, WHO-PCDD/PCB-TEQ and the sum of 6 indicator PCBs (Sum of PCB 28, PCB 52, PCB 101, PCB 138, PCB 153 and PCB 180). Consolidated versions can be downloaded from "EUR-Lex-access to European law" (http://eur-lex.europa.eu) and include all amendments, at present as version of 01.04.2016 [70]. Action levels are set separately for WHO-PCDD/F-TEQ and WHO-PCB-TEQ by Commission Recommendation 2013/711/EU [71], amended by Commission Recommendation2014/663/EU [72].

Also the recent regulations for feed set maximum levels for WHO-PCDD/ F-TEQ, WHO-PCDD/PCB-TEQ and the sum of 6 indicator PCBs. As legal basis, Directive 2002/32/EC of the European Parliament and of the Council provides that any use of products intended for animal feed which contain concentrations of undesirable substances exceeding the maximum levels is prohibited. At present, the consolidated version including amendments of 2015 is available [73]. It includes action thresholds triggering investigations in cases of increased levels of such substances. Maximum and action levels for feed are now listed in the amendments Commission Regulation [EU] No 277/2012 [74] and Commission Regulation [EU] No. 744/2012 [75] which are listed also in the above mentioned consolidated version [ref. [73]].

\section{Conclusion}

Food is the most important source of human exposure to PCDD/PCDF and PCBs. Animal feed contributes significantly to the contamination of food of animal origin. With regard to the huge volumes of feed and food traded on the global market, it is important to continuously control these products for possible dioxin contamination. Only by analyses of high numbers of samples can the shift in trends be detected early enough to prevent widespread contamination. The cost of these analyses is generally small in comparison to the economic costs of a full-blown contamination incident. Seasonal trends require repeated analysis through the year. Several examples show that small companies can cause severe economic consequences if a high contamination in feed is detected quite late in processed food of animal origin on the market. Regulations and monitoring programs were developed and are important to reduce risks and exposure. The detective work to identify sources is a complex process.

\section{Acknowledgements}

The careful review of this paper by Alwyn Fernandes (Food and Environment Research Agency [Fera], York, UK), Heidelore Fiedler (Man-Technology-Environment Research Centre [MTM Research Centre], University of Örebro, Sweden) and Alexander Schächtele and Katharina Djuchin (EU Reference Laboratory for Dioxins and PCBs in Feed and Food, Freiburg, Germany) is gratefully acknowledged.

\section{References}

[1] Rose, M. and Fernandes, A., Eds. (2013) Persistent Organic Pollutants and Toxic 
Metals in Foods. Woodhead Publishing Series in Food Science, Technology and Nutrition, Number 247. https://doi.org/10.1533/9780857098917

[2] Malisch, R. and Kotz, A. (2014) Dioxins and PCBs in Feed and Food-Review from European Perspective. Science of the Total Environment, 491-492, 2-10.

https://doi.org/10.1016/j.scitotenv.2014.03.022

[3] Hoogenboom, R., Traag, W., Fernandes, A. and Rose, M. (2015) European Developments Following Incidents with Dioxins and PCBs in the Food and Feed Chain. Food Control, 50, 670-683. https://doi.org/10.1016/j.foodcont.2014.10.010

[4] Hens, B., Dyke, P.H. and Hens, L. (2016) What Can We Learn from "Dioxin Incidents"? International Journal of Environment and Pollution, 60, 34-62. https://doi.org/10.1504/IJEP.2016.082112

[5] Malisch, R. (1998) Increase of PCDD/F Contamination of Milk and Butter in Germany by Use of Contaminated Citrus Pulp as Component in Feed. Organohalogen Compounds, 38, 65-70.

[6] Malisch, R., Bruns-Weller, E., Knoll, A., Fuerst, P., Mayer, R. and Wiesmueller, T. (2000) Results of an "Emergency Quality Control Study" as Confirmation of a PCDD/PCDF-Contamination of Milk and Butter Samples. Chemosphere, 40, 1033 1040. https://doi.org/10.1016/S0045-6535(99)00351-3

[7] Malisch, R. (2000) Increase of the PCDD/F-Contamination of Milk, Butter and Meat Samples by Use of Contaminated Citrus Pulp. Chemosphere, 40, 1041-1053. https://doi.org/10.1016/S0045-6535(99)00352-5

[8] Schuler, F., Schmid, P. and Schlatter, Ch. (1997) Transfer of Airborne Polychlorinated Diben-zo-p-dioxins and Dibenzofurans into Dairy Milk. Journal of Agricultural and Food Chemistry, 45, 4162-4167. https://doi.org/10.1021/jf970248g

[9] Commission Directive 98/60/EC of 24 July 1998 Amending Council Directive 74/63/EEC on the Fixing of Maximum Permitted Levels for Undesirable Substances and Products in Feed-Ingstuffs. Official Journal of the European Communities, L 209/50.

[10] Louis Dreyfus Citrus, Press Release 06/25/98. Cause behind Dioxin in Brazilian CPP Identified. http://www.ldcitrus.com/us/news/98003.html

[11] Malisch, R., Berger, B. and Verstraete, F. (1999) Lime as Source for PCDD/F-Contamination of Brazilian Citrus Pulp Pellets (CPPs). Organohalogen Compounds, 41, 51-53.

[12] European Commission (1999) Mission Report on a Mission Carried Out in Brazil from 11 to 15 January 1999 Concerning the Organisation of Official Inspections in the Field of Animal Nutrition: Dioxin Contamination of Citrus Pulp Pellets, XXIV/1005/99 MR Final (21/04/99).

[13] European Commission (1999) Mission Report on a Mission Carried Out in Brazil from 05 to 09 July 1999 Concerning the Organisation of Official Inspections in the Field of Animal Nutrition: Dioxin Contamination of Citrus Pulp Pellets, DG(SANCO)/1198/1999 MR Final (08/10/99).

[14] Torres, J.P.M., Leite, C., Krauss, T. and Weber, R. (2008) A Contaminated Site from the Chlorine/Organochlorine Industry as Source of PCDD/F Contamination of Citrus Pulp Pellets Used as Animal Feed in Europe during the Late 1990s. Organohalogen Compounds, 70, 793-796.

[15] Torres, J.P.M., Leite, C., Krauss, T. and Weber, R. (2013) Landfill Mining from a Deposit of the Chlorine/Organochlorine Industry as Source of Dioxin Contamination of Animal Feed and Assessment of the Responsible Processes. Environmental Science and Pollution Research, 20, 1958-1965.

https://doi.org/10.1007/s11356-012-1073-Z 
[16] Hoogenboom, L.A.P., Kan, C.A., Bovee, T.F.H., van der Weg, G., Onstenk, C. and Traag, W.A. (2004) Residues of Dioxins and PCBs in Fat of Growing Pigs and Broilers Fed Contaminated Feed. Chemosphere, 57, 35-42. https://doi.org/10.1016/j.chemosphere.2004.04.057

[17] Broeckaert, F. and Bernard, A. (2000) Polychlorinated Biphenyls (PCBs) and Dioxins (PCDD/Fs) in the Belgian Contaminated Food Chain: Sources, Profiles and Correlations. Final Report, Federal Ministry of Agriculture, Brussels.

[18] Bernard, A., Broeckaert, F., De Poorter, G., De Cock, A., Hermans, C., Saegerman, C. and Houins, G. (2002) The Belgian PCB/Dioxin Incident: Analysis of the Food Chain Contamination and Health Risk Evaluation. Environmental Research Section, A88, 1-18. https://doi.org/10.1006/enrs.2001.4274

[19] European Commission, Scientific Committee on Food (1999) Opinion on Dioxins in Milk Derived from Cattle Fed on Contaminated Feed in Belgium.

[20] De Poorter, G. (1999) Dioxin Contamination of Animal Feed in Belgium: Cause, Consequences and Actions. Presentation at Dioxin'99, 12-17 September 1999, Venice.

[21] Wahl, K., Kotz, A., Hädrich, J., Malisch, R., Anastassiades, M. and Sigalova, I. (1998) The Guar Gum Case: Contamination with PCP and Dioxins and Analytical Problems. Organohalogen Compounds. http://www.dioxin20xx.org/pdfs/2008/08-301.pdf

[22] Brunner, H. (1990) Untersuchungen zu Herkunft und Vorkommen polychlorierter Dibenzodioxine und Dibenzofurane in der Umwelt. Dissertation, Eber-hard-KarlsUniversität, Tübingen.

[23] Community Reference Laboratory for Dioxins and PCBs in Feed and Food (2007) Correlation between Pentachlorophenol (PCP) and Dioxins in Contaminated Guar gum from India Based on Data as Available on 27 August 2007. Report to the EU Commission.

[24] EU Reference Laboratory for Single Residue Methods (EURL-SRM). http://www.eurl-pesticides.eu/library/docs/srm/meth_QuechersForGuarGum.pdf

[25] Community Reference Laboratory for Dioxins and PCBs in Feed and Food (2007) Proficiency Test (PT) on Determination of Dioxins (PCDD/F), PCBs (Dioxin-Like PCBs and Indicator PCBs) and Pentachlorophenol in Guar Gum Samples. Report, PCDD/F and PCB, 4 November 2008.

[26] Kotz, A., Malisch, R., Wahl, K., Hädrich, J., Adamovic, K., Gerteisen, I., Leswal, S., Podestat, U., Schächtele, J., Stumpf, C., Tritschler, R. and Winterhalter, H. (2009) Proficiency Test on the Determination of PCDD/Fs and PCP in Guar Gum and Follow-Up Analyses. Organohalogen Compounds, 71, 002137-002142.

[27] Community Reference Laboratory for Single Residue Methods (2008) EU Proficiency Test-Residues of Pentachlorophenol (PCP) in Guar Gum Samples. Final Report.

[28] Commission of the European Communities (2007) Final Report of a Mission Carried Out in India from 05 to 11 October 2007 to Gather Information on the Source of Contamination of Guar Gum with Pentachlorophenol and Dioxins and to Assess the Control Measures Put in Place by the Indian Authorities to Avoid a Reoccurrence of This Contamination. DG(SANCO)2007-7619-MR Final.

[29] European Commission (2009) Final Report of a Mission Carried Out in India from 01 to 12 October 2009 in Order to Assess the Control Measures Put in Place by the Indian Authorities to Prevent Contamination of Guar Gum with Pentachlorophenol (PCP) and Dioxins and to Follow-Up the Recommendation of Mission DG (SANCO)2007-7619. DG(SANCO) 2009-8329-MR Final. 
[30] Commission Decision of 29 April 2008 Imposing Special Conditions Governing Guar Gum Originating in or Consigned from India Due to Contamination Risks of Those Products by Pentachlorophenol and Dioxins (2008/352/EC). Official Journal of the European Union, L 117/42.

[31] Commission Implementing Regulation (EU) 2015/175 of 5 February 2015 Laying Down Special Conditions Applicable to the Import of Guar Gum Originating in Or Con-Signed from India Due to Contamination Risks by Pentachlorophenol and Dioxin. Official Journal of the European Union, L 30/10.

[32] Fiedler, H., Cooper, K.R., Bergek, S., Hjelt, M. and Rappe, C. (1997) Polychlorinated Dibenzo-p-Dioxins and Polychlorinated Dibenzofurans (PCDD/PCDF) in Food Samples Collected in Southern Mississippi, USA. Chemosphere, 34, 1411-1419. https://doi.org/10.1016/S0045-6535(97)00438-4

[33] Rappe, C., Bergek, S., Fiedler, H. and Cooper, K.R. (1998) PCDD and PCDF Contamination in Catfish Feed from Arkansas, USA. Chemosphere, 36, 2705-2720. https://doi.org/10.1016/S0045-6535(98)00040-X

[34] Ferrario, J., Byrne, C., Lorber, M., Saunders, P., Leese, W., Dupuy, A., Winters, D., Cleverly, D., Schaum, J., Pinsky, P., Deyrup, C., Ellis, R. and Walcott, J. (1997) A Statistical Survey of Dioxin-Like Compounds in United States Poultry Fat. Organohalogen Compounds, 32, 245-251.

[35] Hayward, D.G., Nortrup, D., Gardner, A. and Clower Jr, M. (1999) Elevated TCDD in Chicken Eggs and Farm-Raised Catfish Fed a Diet with Ball Clay from a Southern United States Mine. Environmental Research Section A, 81, 248-256. https://doi.org/10.1006/enrs.1999.3976

[36] Jobst, H. and Aldag, R. (2000) Dioxine in Lagerstätten-Tonen. Z UmweltchemÖkotox, 12, 2-4. https://doi.org/10.1007/bf03037783

[37] Müller, J.F., Haynes, D., McLachlan, M., Böhme, F., Will, S., Shaw, G.R., Mortimer, M., Sadler, R. and Connell, D.W. (1999) PCDDs, PCDFs, PCBs and HCB in Marine and Estuarine Sediments from Queensland, Australia. Chemosphere, 39, 1707-1721. https://doi.org/10.1016/S0045-6535(99)00065-X

[38] Müller, J.F., Gaus, C., Denisson, N., Haynes, D., Manonmanii, K. and Cumming, J. (1999) Octachlorodibenzodioxin in Sediments from Coastal Areas and Irrigation Drains of Queensland-An Indication for an Unknown PCDD Source. Organohalogen Compounds, 43, 285-288.

[39] Haynes, D., Müller, J.F. and McLachlan, M. (1999) Polychlorinated Dibenzo-pDioxins and Dibenzofurans in Great Barrier Reef (Australia) Dugongs (DUGONG DUGON). Chemosphere, 38, 255-262. https://doi.org/10.1016/S0045-6535(98)00194-5

[40] Horii, Y., van Bavel, B., Kannan, K., Petrick, G., Nachtigall, K. and Yamashita, N. (2008) Novel Evidence for Natural Formation of Dioxins in Ball Clay. Chemosphere, 70, 1280-1289. https://doi.org/10.1016/j.chemosphere.2007.07.066

[41] Malisch, R. (2000) PCDD/F in Kaolinitic Clays and Its Relevance for Feeding Stuff, Food and Cosmetics. Organohalogen Compounds, 47, 326-329.

[42] Hoogenboom, R.L., Zeilmaker, M.J., Kan, K.A., Mengelers, M.B., van Eijkeren, J. and Traag, W.A. (2005) Kaolinic Clay Derived Dioxins in Potato By-Products. Organohalogen Compounds, 67, 1470-1473. https://doi.org/10.1016/j.chemosphere.2009.10.016

[43] Hoogenboom, R., Zeilmaker. M., van Eijkeren, J., Kan, K., Mengelers, M., Luykx, D. and Traag, W. (2010) Kaolinic Clay Derived PCDD/Fs in the Feed Chain from a Sorting Process for Potatoes. Chemosphere, 78, 99-105.

[44] European Commission (2004) Rapid Alert System for Food and Feed. Alert Notifi- 
cation 2004.555, 3 November 2004.

[45] Hoogenboom, L.A.P., Talidda, A., Reeuwijk, N.M., Traag, W.A, Kotz, A., Malisch, R., Moy, G., Tritscher, A., Lee, S.L., Magulova, K. and Fiedler, H. (2011) Are Elevated Dioxin Levels in Milk of Women from Ivory Coast and Congo Due to the Use of Clay During Pregnancy? Organohalogen Compounds, 73, 1026-1029.

[46] United Nations (2013) Stockholm Convention on Persistent Organic Pollutants, Conference of the Parties to the Stockholm Convention on Persistent Organic Pollutants, Sixth Meeting, Geneva, 28 April-10 May 2013, Results of the Global Survey on Concentrations in Human Milk of Persistent Organic Pollutants by the United Nations Environment Programme and the World Health Organization (UNEP/ POPS/COP.6/INF/33).

[47] Van den Berg, M., Kypke, K., Kotz, A., Tritscher, A., Lee, S.Y., Magulova, K., Fiedler, H. and Malisch, R. (2017) WHO/UNEP Global Surveys of PCDDs, PCDFs, PCBs and DDTs in Human Milk and Benefit-Risk Evaluation of Breastfeeding. Archives of Toxicology, 91, 83-96. https://doi.org/10.1007/s00204-016-1802-z

[48] Malisch, R., Kotz, A., Wahl, K, Tritscher, A., Lee, S.Y.,Magulova, K., Fiedler, H., Hoogenboom, L.A.P., Traag, W.A., Talidda, A. and Reeuwijk, N.M. (2011) Contamination of Clays with Dioxins and Possible Consequences for the Food Chain and Bioaccumulation in Humans. 1 st International Conference on Clays and Clay Minerals in Africa and 2nd International Conference on Geophagia in Southern Africa, Bloemfontein, 19-21 October 2011, 381-386.

[49] Reeuwijk, N.M., Talidda, A., Malisch, R., Kotz, A., Tritscher, A., Fiedler, H., Zeilmaker, M.J., Kooijman, M., Wienk, K.J.H., Traag, W.A. and Hoogenboom, L.A.P. (2013) Dioxins (Polychlorinated Dibenzo-p-Dioxins and Polychlorinated DibenzoFurans) in Traditional Clay Products Used during Pregnancy. Chemosphere, 90, 1678-1685. https://doi.org/10.1016/j.chemosphere.2012.09.064

[50] Hoogenboom, R., van Ede, K., Portier, L., Bor, G., Bovee, T. and Traag, W. (2008) The Use of the DR CALUX ${ }^{\bowtie}$ Assay for Identification of Novel Risks. Organohalogen Compounds, 70, 000760-000763.

[51] Traag, W., Kotz, A., van der Weg, G., Malisch, R. and Hoogenboom, R. (2009) Bioassay Directed Detection of Brominated Dioxins in the Feed Additive Cholin Chloride. Organohalogen Compounds, 71, 2195-2198.

[52] Borrello, S., Brambilla,, G., Candela, L., Diletti, G., Gallo, P., Iacovella, M., Iovane, G., Limone, A., Migliorati, G., Pinto, O., Sarnelli, P., Serpe, L., Scortichini, G. and di Domenico, A. (2008) Management of the 2008 "Buffalo Milk Crisis" in the Campania Region under the Perspective of Consumer Protection. Organohalogen Compounds, 70, 000891-000893.

[53] Esposito, M., Serpe, F.P., Neugebauer, F., Cavallo, S., Gallo, P., Colarusso, G., Baldi, L., Iovane, G. and Serpe, L. (2010) Contamination Levels and Congener Distribution of PCDDs, PCDFs and Dioxin-Like PCBs in Buffalo's Milk from Caserta Province (Italy). Chemosphere, 79, 341-348. https://doi.org/10.1016/j.chemosphere.2010.01.025

[54] Tlustos, C. (2009) The Dioxin Contamination Incident in Ireland 2008. Organohalogen Compounds, 71, 001155-001159.

[55] Tlustos, C., Sheridan, M., O’Sullivan, D., Anderson, W. and Flynn, A. (2012) The Dioxin Contamination Incident in Ireland, 2008: Analytical Results and Congener Patterns. Food Additives and Contaminants, 29, 128-138. https://doi.org/10.1080/19440049.2011.615030

[56] Heres, L., Hoogenboom, R., Herbes, R., Traag, W. and Urlings, B. (2010) Tracing and Analytical Results of the Dioxin Contamination Incident in 2008 Originating 
from the Republic of Ireland. Food Additives and Contaminants, 27, 1733-1744. https://doi.org/10.1080/19440049.2010.522598

[57] Marnane, I. (2012) Comprehensive Environmental Review Following the Pork PCB/Dioxin Contamination Incident in Ireland. Journal of Environmental Monitoring, 14, 2551-2556. https://doi.org/10.1039/c2em30374d

[58] European Food Safety Authority (EFSA) (2008) Statement of EFSA on the Risks for Public Health Due to the Presence of Dioxins in Pork from Ireland (Question No EFSA-Q-2008-777), Issued on 10 December 2008. The EFSA Journal, 911, 1-15.

[59] Chemisches und Veterinäruntersuchungsamt (CVUA) Freiburg (2008) Jahresbericht.

[60] Tlustos, C., Anderson, W., Flynn, A. and Pratt, I. (2014) Additional Exposure of the Irish Adult Population to Dioxins and PCBs from the Diet as a Consequence of the 2008 Irish Dioxin Food Contamination Incident. Food Additives \& Contaminants, Part A, 31, 889-904. https://doi.org/10.1080/19440049.2014.893399

[61] European Commission (2008) Summary Minutes of the Standing Committee on the Food Chain and Animal Health, Brussels, 10 December 2008, SANCO-D1(2008) $\mathrm{D} / 412398$.

https://ec.europa.eu/food/sites/food/files/safety/docs/reg-com_toxic_summary1012 2008_en.pdf

[62] Tlustos, C. (2009) The Dioxin Crisis in Ireland 2008-Challenges in Risk Management and Risk Communication. Organohalogen Compounds, 71, 001152-001154.

[63] European Commission. Food Safety, Chemical Safety, Contaminants. Dioxins in Pork Meat in Ireland. https:/ec.europa.eu/food/safety/chemical_safety/contaminants/catalogue/dioxins_en

[64] Evans, R. (2008) Review of the 2008 Irish Dioxin Incident. Food Safety Authority of Ireland.

https://www.fsai.ie/uploadedFiles/News_Centre/Events/archive/Rhodri\%20Evans\% 20FSAI.pdf

[65] Der Dioxinskandalimzeitlichen Ablauf (2011) Food \& Hygiene. Behr's Verlag, Hamburg, Ausgabe 2, Seite 2-3.

[66] European Commission. Food Safety, Chemical Safety, Contaminants. Dioxin Contamination Incident in Germany Closing Information Note.

https://ec.europa.eu/food/sites/food/files/safety/docs/cs_contaminants_catalog_dio xin_de-incident_information_note.pdf

[67] Chemisches und Veterinäruntersuchungsamt Münsterland-Emscher-Lippe (CVUAMEL), Jahresbericht 2011.

[68] Weber, R. and Watson, A. (2011) Assessment of the PCDD/PCDF Fingerprint of the Dioxin Food Scandal from Bio-Diesel in Germany and Possible PCDD/F Sources. Organohalogen Compounds, 73, 400-403.

[69] Communication from the Commission to the Council, the European Parliament and the Economic and Social Committee: Community Strategy for Dioxins, Furans and Polychlorinated Biphenyls (2001/C 322/02), (COM(2001) 593 Final). Official Journal of the European Communities, C 322/2.

[70] Commission Regulation (EC) No 1881/2006 of 19 December 2006 Setting Maximum Levels for Certain Contaminants in Foodstuffs, Consolidated Version of 01.04.2016, 2006R1881-EN-01.04.2016-020.001, Comprising as Latest Amendment Commission Regulation (EU) 2016/239 of 19 February 2016 Amending Regulation (EC) No 1881/2006 as Regards Maximum Levels of Tropane Alkaloids in Certain Cereal-Based Foods for Infants and Young Children. 
http://eur-lex.europa.eu/legal-content/EN/TXT/PDF/?uri=CELEX:02006R1881-201 60401\&from $=\mathrm{EN}$

[71] Commission Recommendation of 3 December 2013 on the Reduction of the Presence of Dioxins, Furans and PCBs in Feed and Food (2013/711/EU). Official Journal of the European Communities, L 323/37.

[72] Commission Recommendation of 11 September 2014 Amending the Annex to Recommendation 2013/711/EU on the Reduction of the Presence of Dioxins, Furans and PCBs in Feed and Food (2014/663/EU). Official Journal of the European Communities, L 272/17.

[73] Directive 2002/32/EC of the European Parliament and of the Council of 7 May 2002 on Undesirable Substances in Animal Feed, Consolidated Version of 27.02.2015, 2002L0032-EN-27.02.2015-019.001.

http://eur-lex.europa.eu/legal-content/EN/TXT/?qid=1492680744977\&uri=CELEX: 02002L0032-20150227

[74] Commission Regulation (EU) No 277/2012 of 28 March 2012 Amending Annexes I and II to Directive 2002/32/EC of the European Parliament and of the Council as Regards Maximum Levels and Action Thresholds for Dioxins and Polychlorinated Biphenyls. Official Journal of the European Union, L 91/1.

[75] Commission Regulation (EU) No 744/2012 of 16 August 2012 Amending Annexes I and II to Directive 2002/32/EC of the European Parliament and of the Council as Regards Maximum Levels for Arsenic, Fluorine, Lead, Mercury, Endosulfan, Dioxins, Ambrosia spp., Diclazuril and Lasalocid A Sodium and Action Thresholds for Dioxins. Official Journal of the European Union, L 219/5.

Submit or recommend next manuscript to SCIRP and we will provide best service for you:

Accepting pre-submission inquiries through Email, Facebook, LinkedIn, Twitter, etc. A wide selection of journals (inclusive of 9 subjects, more than 200 journals) Providing 24-hour high-quality service User-friendly online submission system Fair and swift peer-review system Efficient typesetting and proofreading procedure Display of the result of downloads and visits, as well as the number of cited articles Maximum dissemination of your research work

Submit your manuscript at: http://papersubmission.scirp.org/

Or contact jep@scirp.org 